\title{
Emissions Trading, Capital Flows and the Kyoto Protocol*
}

\author{
Warwick J. McKibbin \\ Australian National University and \\ The Brookings Institution \\ Martin T. Ross \\ U.S. Environmental Protection Agency \\ Robert Shackleton \\ U.S. Environmental Protection Agency \\ and \\ Peter J. Wilcoxen \\ University of Texas at Austin and \\ The Brookings Institution
}

* The authors are grateful for financial support from the Brookings Institution and the U.S. Environmental Protection Agency through Cooperative Agreement CX 826555-01-1. The views expressed in this paper are those of the authors and should not be interpreted as reflecting the views of any funding organizations or the organizations with which they are affiliated 


\begin{abstract}
We use an econometrically estimated multi-region, multi-sector general equilibrium model of the world economy to examine the effects of the tradable emissions permit system proposed in the 1997 Kyoto protocol, under various assumptions about that extent of international permit trading. We focus, in particular, on the effects of the system on international trade and capital flows. Our results suggest that consideration of these flows significantly affects estimates of the domestic effects of the emissions mitigation policy, compared with analyses that ignore international capital flows.
\end{abstract}

Warwick J. McKibbin

Division of Economics

Asian Pacific School of Economics \& Management

\& Research School of Pacific \& Asian Studies

Australian National University

ACT 0200

AUSTRALIA

Wmckibbin@brook.edu

Robert Shackleton

Policy Office

Environmental Protection Agency

Washington DC 20460

USA
Martin Ross

Policy Office

Environmental Protection Agency

Washington DC 20460

USA
Peter J. Wilcoxen

Economics Department

University of Texas- Austin

Austin TX 78712

USA 


\section{Introduction}

As part of an effort to reduce global emissions of greenhouse gases (GHGs) that are expected to contribute to a significant warming of the earth's climate, the Kyoto Protocol to the United Nations Framework Convention on Climate Change, signed in Kyoto in December 1997, includes binding GHG emissions targets for the world's industrial economies ("Annex I" countries) for the period 2008-2012. The Protocol also provides for international trading of emission allowances among the countries that accept binding targets, in recognition of the theoretical efficiency benefits of allowing emission reductions to be obtained at least cost. In addition, the Protocol provides for a Clean Development Mechanism, under which agents from industrial countries can earn emission credits for certified reductions from investments in "clean development" projects in developing countries that have not taken on binding targets.

In this paper we present estimates of the potential economic effects of the Kyoto Protocol, using the G-Cubed multi-region, multi-sector intertemporal general equilibrium model of the world economy. ${ }^{1}$ We examine and compare four potential implementations of the Protocol involving varying degrees of international permit trading, focusing particularly on short term dynamics and on the effects of the policies on output, exchange rates and international flows of goods and financial capital. We present calculations of some of the gains from allowing international permit trading, and examine the sensitivity of the results to changes in the most important assumptions.

\section{Model Structure}

In this section we give a necessarily brief overview of the key features of the model underlying this study, that are important in understanding the results. For a more complete coverage of the model, please see McKibbin and Wilcoxen (1995b). ${ }^{2}$

\footnotetext{
${ }^{1}$ G-Cubed stands for "Global General Equilibrium Growth Model." An earlier draft of this paper used version 31 of the model. This draft uses version 39, which includes significant data updates and has emission coefficients on gas and oil separately rather than on the crude oil and gas extraction sector
} 
The G-Cubed model consists of a set of eight regional general equilibrium models linked by consistent international flows of goods and assets. We assume that each region consists of a representative household, a government sector, a financial sector, twelve industries, and two sectors producing capital goods for the producing industries and households, respectively. The regions and sectors are listed in Table 1. The regions are similar in structure (that is, they consist of similar agents solving similar problems), but they differ in endowments, behavioral parameters and government policy variables. ${ }^{3}$ In the remainder of this section we present the key features of the regional models.

\subsection{Producer Behavior}

Within a region, each producing sector is represented by a single firm which chooses its inputs and investment in order to maximize its stock market value subject to a multiple-input production function and a vector of prices it takes to be exogenous. We assume that output can be represented by a constant elasticity of substitution (CES) function of inputs of capital, labor, energy and materials:

$$
Q_{i}=A_{i o}\left(\sum_{j=K, L, E, M} \delta_{i j}^{l / \sigma_{i o}} X_{i j}^{\left(\sigma_{i 0^{-}}-l\right) \sigma_{i o}}\right)^{\frac{\sigma_{i o}}{\left(\sigma_{i 0^{-}}-1\right)}}
$$

where $Q_{i}$ is output, $X_{i j}$ is industry i's use of input $\mathrm{j}$ (i.e. K,L,E and M), and $\mathrm{A}_{\mathrm{iO}}, \delta_{\mathrm{ij}}$, and $\sigma_{\mathrm{iO}}$ are parameters. Energy and materials, in turn, are CES aggregates of inputs of intermediate goods: energy is composed of the first five goods in Table 1 and materials is composed of the remaining seven:

$$
X_{i E}=A_{i E}\left(\sum_{j=1}^{5} \delta_{i j}^{l / \sigma_{i E}} X_{i j}^{\left(\sigma_{i E}-l\right) / \sigma_{i E}}\right)^{\frac{\sigma_{i E}}{\left.\sigma_{i E}-l\right)}}
$$

${ }^{2}$ This and other papers describing the model are available at http:Iwww.msgpl.com.au.

${ }^{3}$ This is enough to allow the regions to be quite different from one another. For example, even though all of the regions consist of the twelve industries in Table 1 we do not impose any requirement that the output of a particular industry in one country be identical to that of another country. The industries are themselves aggregates of smaller sectors and the aggregation weights can be very different across countries: the output of the durable goods sector in Japan will not be identical to that of the United States. The fact that these goods are not identical is reflected in the assumption (discussed further below) that foreign and domestic goods are generally imperfect substitutes. 


$$
X_{i M}=A_{i M}\left(\sum_{j=6}^{12} \delta_{i j}^{l / \sigma_{i M}} X_{i j}^{\left(\sigma_{i M}-1\right) / \sigma_{i M}}\right)^{\frac{\sigma_{i M}}{\left(\sigma_{i M}-1\right)}}
$$

Intermediate goods are, in turn, functions of domestically produced and imported goods.

We use a nested system of CES equations rather than a more flexible functional form because data limitations make even the CES model a challenge to estimate. In principle, to estimate a more flexible specification we would need time-series price and quantity data for 14 inputs (twelve goods plus capital and labor) in each of 96 industries (12 industries in 8 regions). Unfortunately, no country collects annual data on intermediate inputs, and most developing countries collect almost no industry data at all.

The scarcity of input-output data requires us to restrict the model further by imposing the assumption that each industry has the same energy, materials and KLEM substitution elasticities no matter where it is located (although the elasticities differ across industries). ${ }^{4}$ However, even though the substitution elasticities are identical across countries, the overall production models differ because the CES input weights are taken from the latest available input-output data for each country or region. ${ }^{5}$ Thus, the durable goods sectors in the United States and Japan, for example, have identical substitution elasticities but different sets of input weights. The consequence of this is that the cost shares of inputs to a given industry are based on data for the country in which the industry operates, but the industry's response to a given percentage increase in an input price is identical across countries. Taken together, these assumptions are equivalent to assuming that all regions share production methods that differ in first-order properties but have identical second-order characteristics. This approach is intermediate between one extreme of assuming that the regions share common technologies and the other extreme of allowing the technologies to differ across regions in arbitrary ways.

\footnotetext{
${ }^{4}$ This assumption is consistent with the available econometric evidence (see for example Kim and Lau, 1994).

${ }^{5}$ Input-output tables were not available for the regions in the model larger than individual countries. The input weights for those regions were based on data for the United States.
} 
The regions also differ in their endowments of primary factors, their government policies, and patterns of final demands, so although they share some common parameters they are not simple replicas of one another.

To estimate the elasticities we have constructed time-series data on prices, industry inputs, outputs and value-added for the country for which we were able to obtain the longest series of input-output tables: the United States. The following is a sketch of the approach; complete details are contained in McKibbin and Wilcoxen (forthcoming).

We began with the benchmark input-output transactions tables produced by the Bureau of Economic Analysis (BEA) for years 1958, 1963, 1967, 1972, 1977 and 1982. ${ }^{6}$ The conventions used by the BEA have changed over time, so the raw tables are not completely comparable. We transformed the tables to make them consistent and aggregated them to twelve sectors. We then shifted consumer durables out of final consumption and into fixed investment. ${ }^{7}$ We also increased the capital services element of final consumption to account for imputed service flows from durables and owner-occupied housing. Finally, we used a data set constructed by Dale Jorgenson and his colleagues to decompose the value-added rows of the tables, ${ }^{8}$ and a data set produced by the Office of Employment Projections at the Bureau of Labor Statistics to provide product prices.

Table 2 presents estimates of the substitution elasticities for each industry; standard errors are shown in parentheses. ${ }^{9}$ The elasticity of substitution between capital, labor, energy and

\footnotetext{
${ }^{6}$ A benchmark table also exists for 1947 but it has inadequate final demand detail for our purposes. Subsequent to our estimation work a 1987 table has become available.

${ }^{7}$ The National Income and Product Accounts (and the benchmark input-output tables as well) treat purchases of consumer durables as consumption rather than investment.

${ }^{8}$ This data set is the work of several people over many years. In addition to Dale Jorgenson, some of the contributors were Lau Christiansen, Barbara Fraumeni, Mun Sing Ho and Dae Keun Park. The original source of data is the Fourteen Components of Income Tape produced by the Bureau of Economic Analysis. See Ho (1989) for more information.

${ }^{9}$ The parameters were estimated using systems of factor demand equations derived from the KLEM portion of the production function and the dual versions of the energy and materials tiers.
} 
materials (KLEM) for each sector, parameter $\sigma_{\mathrm{iO}}$ in (1), is shown in the column labeled "Output"; the columns labeled "Energy" and "Materials" give the elasticities of substitution within the energy and materials node, $\sigma_{\mathrm{iE}}$ and $\sigma_{\mathrm{iM}}$.

A number of the estimates had the wrong sign or could not be estimated (the estimation procedure failed to converge). In such cases we examined the data and imposed elasticities that seemed appropriate; these values are shown in the table without standard errors. ${ }^{10}$ For most of the imposed parameters, the data suggest complementarities among inputs, which is incompatible with the CES specification. If more data were available, it would be worthwhile to use a more flexible functional form.

Finally, in order to improve the model's ability to match physical flows of energy we have imposed lower energy and output elasticities in a few sectors. These are shown in the columns labeled "Imposed." For example, the estimated KLEM elasticity in the electric sector was 0.763 but we have imposed an elasticity of 0.2 in order to help the model more accurately track the physical quantities of energy inputs and outputs to the sector.

Maximizing the firm's short run profit subject to its capital stock and the production functions above gives the firm's factor demand equations. At this point we add two further levels of detail: we assume that domestic and imported inputs of a given commodity are imperfect substitutes, and that imported products from different countries are imperfect substitutes for each other. Given the model's level of aggregation these are more a simple acknowledgment of reality than an assumption. ${ }^{11}$ Thus, the final decision the firm must make is the fraction of each of its inputs to buy from each region, including the firm's home country. Due to data constraints we impose a unitary elasticity of substitution between domestic and foreign goods. The significance of this is examined in Section 5, which presents results for several alternative elasticities. In

\footnotetext{
${ }^{10}$ For this study we also imposed lower KLEM substitution elasticities on a few of the energy industries where it seemed that the estimated elasticities might overstate the true ability of the industry to shift factors of production.

${ }^{11}$ This approach is based on the work of Armington (1969).
} 
addition, we assume that all agents in the economy have identical preferences over foreign and domestic varieties of each particular commodity. ${ }^{12}$ We parameterize this decision using trade shares based on aggregations of the United Nations international trade data for $1987 .{ }^{13}$ The result is a system of demand equations for domestic output and imports from each other region.

In addition to buying inputs and producing output, each sector must also choose its level of investment. We assume that capital is specific to each sector, it depreciates geometrically at rate $\delta$, and that firms choose their investment paths in order to maximize their market value. Following the cost of adjustment models of Lucas (1967), Treadway (1969) and Uzawa (1969) we assume that the investment process is subject to rising marginal costs of installation. To formalize this we adopt Uzawa's approach by assuming that in order to install $\mathrm{J}$ units of capital the firm must buy a larger quantity, I, that depends on its rate of investment $(\mathrm{J} / \mathrm{K})$ as follows:

$$
I=\left(1+\frac{\phi}{2} \frac{J}{K}\right) J
$$

where $\phi$ is a non-negative parameter and the factor of two is included purely for algebraic convenience. The difference between $\mathrm{J}$ and I may be interpreted many ways; we will view it as installation services provided by the capital vendor.

Setting up and solving the firm's investment problem yields the following expression for investment in terms of parameters, the current capital stock, and marginal $q$ (the ratio of the marginal value of a unit of capital to its purchase price):

$$
I=\frac{1}{2 \phi}\left(q^{2}-1\right) K
$$

Following Hayashi (1979), and building on a large body of empirical evidence suggesting that a nested investment function fits the data much better than a pure $q$-theory model, we extend (5) by writing $I$ as a function not only of $q$, but also of the firm's current profit, $\pi$, adjusted by the

\footnotetext{
12 Anything else would require time-series data on imports of products from each country of origin to each industry, which is not only unavailable but difficult to imagine collecting.

${ }^{13}$ Specifically, we aggregate up from data at the 4-digit level of the Standard International Trade Classification.
} 
investment tax credit, $\tau_{4}$ :

$$
I=\alpha_{2} \frac{1}{2 \phi}\left(q^{2}-1\right) K+\left(1-\alpha_{2}\right) \frac{\pi}{\left(1-\tau_{4}\right) P^{I}}
$$

This improves the empirical behavior of the specification and is consistent with the existence of firms that are unable to borrow and therefore invest purely out of retained earnings. The parameter $a_{2}$ was taken to be 0.3 based on a range of empirical estimates reported by McKibbin and Sachs (1991).

In addition to the twelve industries discussed above, the model also includes a special sector that produces capital goods. This sector supplies the new investment goods demanded by other industries. Like other industries, the investment sector demands labor and capital services as well as intermediate inputs. We represent its behavior using a nested CES production function with the same structure as that used for the other sectors, and we estimate the parameters using price and quantity data for the final demand column for investment. As before, we use U.S. data to estimate the substitution elasticities and country or region data to determine the share parameters.

\subsection{Households}

Households consume goods and services in every period and also demand labor and capital services. Household capital services consist of the service flows of consumer durables plus residential housing. Households receive income by providing labor services to firms and the government, and by holding financial assets. In addition, they receive imputed income from ownership of durables and housing, and they also may receive transfers from their region's government.

Within each region we assume household behavior can be modeled by a representative agent with an intertemporal utility function of the form:

$$
U_{t}=\int_{t}^{\infty}(\ln C(s)+\ln G(s)) e^{-\theta(s-t)} d s
$$

where $C(s)$ is the household's aggregate consumption of goods at time $s, G(s)$ is government 
consumption, which we take to be a measure of public goods supply, and $\theta$ is the rate of time preference and is equal to 2.5 percent. ${ }^{14}$ The household maximizes its utility subject to the constraint that the present value of consumption be equal to human wealth plus initial financial assets. Human wealth, $H$, is the present value of the future stream of after-tax labor income and transfer payments received by households. Financial wealth, $F$, is the sum of real money balances, real government bonds in the hands of the public (Ricardian neutrality does not hold in this model because some consumers are liquidity-constrained; more on this below), net holdings of claims against foreign residents and the value of capital in each sector. A full derivation can be found in McKibbin and Sachs (1991) and McKibbin and Wilcoxen (forthcoming).

Under this specification, it is easy to show that the desired value of each period's consumption is equal to the product of the time preference rate and household wealth:

$$
P^{C} C=\theta(F+H)
$$

There has, however, been considerable debate about whether the actual behavior of aggregate consumption is consistent with the permanent income model. ${ }^{15}$ Based on a wide range of empirical evidence in the macroeconomics literature (see Campbell and Mankiw, 1990), we impose that only a fraction $\beta$ of all consumers choose their consumption to satisfy (8) and that the remainder consume based entirely on current after-tax income. We have deliberately chosen to depart from the theoretical elegance of (8) because we are evaluating real-world policy and it is absolutely clear from empirical data that (8) alone is not a satisfactory model of aggregate consumption. This is an important difference between our approach and many of the other models used to study climate change policy, where theoretical elegance has often been given greater importance than realism. Whenever we have had to choose between theoretical elegance and empirical relevance, we have chosen the latter. ${ }^{16}$

\footnotetext{
14 This specification imposes the restriction that household decisions on the allocations of expenditure among different goods at different points in time be separable. Also, since utility is additive in the logs of private and government consumption, changes in government consumption will have no effect on private consumption decisions. ${ }^{15}$ Some of the key papers in this debate are Hall (1978), Flavin (1981), Hayashi (1982), and Campbell and Mankiw (1990).

${ }^{16}$ One complication of introducing a nested specification for consumption is that traditional welfare evaluations are difficult. However, we view it as far more important to take empirical facts into account than for it to be easy to
} 
The empirical finding that pure permanent income models such as (8) are rejected by the data while nested functions that include a large weight on current income fit much better could be interpreted in various ways, including the presence of liquidity-constrained households or households with myopic expectations. For the purposes of this paper we will not adopt any particular explanation but simply take $\beta$ to be an exogenous constant. ${ }^{17}$ This produces the final consumption function shown below:

$$
P^{C} C=\beta \theta\left(F_{t}+H_{t}\right)+(1-\beta) \gamma I N C
$$

where $\gamma$ is the marginal propensity to consume for the households consuming out of current income. Following McKibbin and Sachs (1991) we take $\beta$ to be 0.3 in all regions. ${ }^{18}$

Within each period, the household allocates expenditure among goods and services in order to maximize $C(s)$, its intratemporal utility index. In this version of the model we assume that $C(s)$ may be represented by a nested CES function. At the top tier, consumption is composed of inputs of capital services, labor, energy and materials. Energy and materials, in turn, are CES aggregates of inputs of individual goods. ${ }^{19}$ The elasticities of substitution at the energy and materials tiers were estimated to be 0.8 and 1.0, respectively. In this version of the model the top tier elasticity has been imposed to be unity.

Finally, the supply of household capital services is determined by consumers themselves who invest in household capital. We assume households choose the level of investment to maximize the present value of future service flows (taken to be proportional to the household capital stock), and that investment in household capital is subject to adjustment costs. In other words, the household investment decision is symmetrical with that of the firms.

\footnotetext{
calculate equivalent variations.

${ }^{17}$ One side effect of this specification is that it will prevent us from using equivalent variation or other welfare measures derived from the expenditure function. Since the behavior of some of the households is implicitly inconsistent with the previous equation, either because the households are at corner solutions or for some other reason, aggregate behavior is inconsistent with the expenditure function derived from our utility function.

${ }^{18}$ Our value is somewhat lower than Campbell and Mankiw's estimate of 0.5.

${ }^{19}$ This specification has the undesirable effect of imposing unitary income and price elasticities. There is abundant empirical evidence against this assumption and we intend to generalize it in future work.
} 


\subsection{Labor Market Equilibrium}

We assume that labor is perfectly mobile among sectors within each region but is immobile between regions. Thus, within each region wages will be equal across sectors. The nominal wage is assumed to adjust slowly according to an overlapping contracts model (adjusted for different labor market institutional structures in different economies) where nominal wages are set based on current and expected inflation and on economy-wide labor demand relative to labor supply. In the long run labor supply, which is specified in terms of labor efficiency units, is given by the exogenous rate of population growth, but in the short run the hours worked can fluctuate depending on the demand for labor. For a given nominal wage, the demand for labor will determine short-run unemployment.

Relative to other general equilibrium models, this specification is unusual in allowing for involuntary unemployment. We adopt this approach because we are particularly interested in the transition dynamics of the world economy. As in the case of consumption behavior, we are deliberately choosing to make the model less theoretically elegant in order to better represent reality. The alternative of assuming that all economies are always at full employment, which might be fine for a long-run model, is clearly inappropriate during the first few years after a shock. Unemployment is very likely to be an important part of the adjustment of the global economy of the short to medium term, and it is hard to justify assuming it away simply because it is inconvenient for theory. This is by no means a new idea, but despite its long and empirically robust standing in mainstream macroeconomics it is rarely implemented in a general equilibrium model.

\subsection{Government}

We take each region's real government spending on goods and services to be exogenous and assume that it is allocated among final goods, services and labor in fixed proportions, which we set to 1990 values for each region. Total government spending includes purchases of goods and services plus interest payments on government debt, investment tax credits and transfers to households. Government revenue comes from sales, corporate, and personal income taxes, and 
from issuing government debt. In addition, there can be taxes on externalities such as carbon dioxide emissions.

The difference between revenues and total spending gives the budget deficit. Deficits are financed by sales of government bonds. We assume that agents will not hold bonds unless they expect the bonds to be serviced, and accordingly impose a transversality condition on the accumulation of public debt in each region that has the effect of causing the stock of debt at each point in time to be equal to the present value of all future budget surpluses from that time forward. This condition alone, however, is insufficient to determine the time path of future surpluses: the government could pay off the debt by briefly raising taxes a lot; it could permanently raise taxes a small amount; or it could use some other policy. We assume that the government levies a lump sum tax in each period equal to the value of interest payments on the outstanding debt. In effect, therefore, any increase in government debt is financed by consols, and future taxes are raised enough to accommodate the increased interest costs. Thus, any increase in the debt will be matched by an equal present value increase in future budget surpluses. Other fiscal closure rules are possible such as always returning to the original ratio of government debt to GDP. These closures have interesting implications but are beyond the scope of this paper.

Finally, because our wage equation depends on the rate of expected inflation, we need to include money supply and demand in the model. The supply of money is determined by the balance sheet of the central bank and is exogenous. We assume that money demand arises from the need to carry out transactions and takes the following form:

$$
M=P Y i^{\varepsilon}
$$

where $M$ is money, $P$ is the price level, $Y$ is aggregate output, $i$ is the interest rate and $\varepsilon$ is the interest elasticity of money demand. Following McKibbin and Sachs (1991) we take $\varepsilon$ to be -0.6 .

\subsection{International Trade and Capital Asset Flows}

The eight regions in the model are linked by flows of goods and assets. Each region may import each of the 12 goods from potentially all of the other seven regions. In terms of the way 
international trade data is often expressed, our model endogenously generates a set of twelve 8x8 bilateral trade matrices, one for each good. The values in these matrices are determined by the import demands generated within each region.

The trade balance in each economy is the result of intertemporal saving and investment decisions of households, firms and governments. Trade imbalances are financed by flows of assets between countries: countries with current account deficits have offsetting inflows of financial capital; countries with surpluses have matching capital outflows. Global net flows are constrained to be zero. We assume that asset markets are perfectly integrated and that financial capital is freely mobile. ${ }^{20}$ Under this assumption, expected returns on loans denominated in the currencies of the various regions must be equalized period to period according to a set of interest arbitrage relations of the following form:

$$
i_{k}+\mu_{k}=i_{j}+\mu_{j}+\frac{\dot{E}_{k}^{j}}{E_{k}^{j}}
$$

where $i_{k}$ and $i_{j}$ are the interest rates in countries $k$ and $j, \mu_{k}$ and $\mu_{j}$ are exogenous risk premiums demanded by investors (possibly zero), and $E_{k}^{j}$ is the exchange rate between the two currencies. The risk premiums are calculated in the course of generating the model's baseline and are generally held constant in simulations. Thus, if, in the base year, capital tended not to flow into a region with relatively high interest rates, it will not do so during the simulation. Finally, we also assume that OPEC chooses its foreign lending in order to maintain a desired ratio of income to wealth subject to a fixed exchange rate with the U.S. dollar.

Although financial capital is perfectly mobile, it is important to remember that physical capital is specific to sectors and regions and is hence immobile. The consequence of having mobile financial capital and immobile physical capital is that there can be windfall gains and losses to owners of physical capital. For example, if a shock adversely affects profits in a particular industry, the physical capital stock in that sector will initially be unaffected. Its value,

\footnotetext{
${ }^{20}$ The mobility of international capital is a subject of considerable debate; see Gordon and Bovenberg (1994) or Feldstein and Horioka (1980).
} 
13

however, will immediately drop by enough to bring the rate of return in that sector back to into equilibrium with that in the rest of the economy. Because physical capital is subject to adjustment costs, the portion of any inflow of financial capital that is invested in physical capital will also be costly to shift once it is in place. ${ }^{21}$

\subsection{Constructing the Base Case}

To solve the model, we first normalize all quantity variables by the economy's endowment of effective labor units. This means that in the steady state all real variables are constant in these units although the actual levels of the variables will be growing at the underlying rate of growth of population plus productivity. Next, we must make base-case assumptions about the future path of the model's exogenous variables in each region. In all regions we assume that the long run real interest rate is 5 percent, tax rates are held at their 1990 levels and that fiscal spending is allocated according to 1990 shares. Population growth rates vary across regions as shown in Table 3.

A crucial group of exogenous variables are productivity growth rates by sector and country. The baseline assumption in G-Cubed is that the pattern of technical change at the sector level is similar to the historical record for the United States (where data is available). In regions other than the United States, however, the sector-level rates of technical change are scaled up or down in order to match the region's observed average rate of aggregate productivity growth over the past two decades. This approach attempts to capture the fact that the rate of technical change varies considerably across industries while reconciling it with regional differences in overall growth. ${ }^{22}$ This is clearly a rough approximation; if appropriate data were available it would be better to estimate productivity growth for each sector in each region.

Given these assumptions, we solve for the model's perfect-foresight equilibrium growth

\footnotetext{
${ }^{21}$ Financial inflows are not necessarily invested entirely in physical capital. Because of adjustment costs, part of any given inflow goes toward bidding up the stock market value of existing assets.

${ }^{22}$ For a more detailed discussion of the importance of accounting for heterogeneity in sector-level productivity growth rates see Bagnoli, McKibbin and Wilcoxen (1996).
} 
path over the period 1990-2050. This a formidable task: the endogenous variables in each of the sixty periods number over 6,000 and include, among other things: the equilibrium prices and quantities of each good in each region, intermediate demands for each commodity by each industry in each region, asset prices by region and sector, regional interest rates, bilateral exchange rates, incomes, investment rates and capital stocks by industry and region, international flows of goods and assets, labor demanded in each industry in each region, wage rates, current and capital account balances, final demands by consumers in all regions, and government deficits. ${ }^{23}$ At the solution, the budget constraints for all agents are satisfied, including both intratemporal and intertemporal constraints.

\section{The Effects of the Kyoto Protocol}

We now explore the effects of the Kyoto Protocol in five different scenarios. In the first, the United States meets its commitment under the Protocol but no other regions take action. This scenario is presented not as a practical proposition but as a benchmark against which multilateral scenarios can be compared. In the remaining four scenarios we examine the effects of the Protocol when all regions meet their commitments but the extent of international emissions permit trading varies.

The model only accounts for emissions of carbon dioxide from fossil fuel combustion, while the Protocol specifies targets for all greenhouse gases in carbon equivalent units. ${ }^{24}$ Accordingly, we make the simplifying assumption that reductions in fossil-related carbon dioxide emissions will be made in proportion to the reductions required in total GHGs, and set the carbon

\footnotetext{
${ }^{23}$ Since the model is solved for a perfect-foresight equilibrium over a 60 year period, the numerical complexity of the problem is on the order of 60 times what the single-period set of variables would suggest. We use software developed by McKibbin (1992) for solving large models with rational expectations on a personal computer.

${ }^{24}$ The carbon equivalent units are specified in terms of the 100-year global warming potentials (GWPs) of carbon; e.g. a ton of methane emissions are counted as the equivalent of 21 tons of carbon (or 21 times 3.67 tons of carbon dioxide), since a ton of methane contributes roughly the same amount of radiative forcing over a century as 21 tons of carbon in the form of carbon dioxide. The permits are sold and used annually; we do not allow for banking or borrowing of emissions between years within the 2008-2012 budget period although this is permitted under the Protocol.
} 
target accordingly. For instance, the Protocol specifies a 2008-2012 average annual target for the United States of $93 \%$ of 1990 GHG emissions, which were approximately 1,600 million metric tons of carbon equivalents (MMTCe). The overall U.S. greenhouse gas target is therefore roughly 1,490 MMTCe. However, the share of fossil-related carbon dioxide in this target will depend on the marginal cost schedules for all of the gases, not just CO2. To simplify, we assume that the fossil CO2 target will be $93 \%$ of 1990 fossil CO2 emissions, or approximately 1247 MMTC. This approach ignores the likelihood that relatively inexpensive GHG reductions will be available from non-energy and non-carbon sources, but provides a useful first approximation of the costs of achieving the Kyoto targets.

In each scenario, Annex I regions hold annual auctions of the specified quantity of carbon emissions permits in each of the years from 2008 to $2020 .^{25}$ The permits are required for the use of fossil fuels (coal, refined oil and natural gas) in proportion to the average carbon content per physical unit of each fuel. Revenues from the permit sales are assumed to be returned to households via a deficit-neutral lump sum rebate. ${ }^{26}$ The policy is announced in 2000 so that forward-looking agents have a nearly decade to anticipate the policy and adapt to it.

Because G-Cubed represents each region as a competitive market economy in dynamic equilibrium with other regions, its representation of the former Soviet Bloc does not capture the shock associated with the institutional collapse of the formerly planned economy, the consequent dramatic decrease in emissions, or the fact that the region's emissions are likely to be well below the limit mandated by the Kyoto Protocol a decade from now. However, except for the reunification of Germany and the extensive development of parts of Eastern Europe, and the fact that crude oil and gas exports have continued, much of the region has remained substantially

\footnotetext{
${ }^{25}$ Beyond 2020 the supply of permits is allowed to increase at such a rate as to leave the real permit price at its 2020 value.

${ }^{26}$ The rebate is chosen to leave the deficit unchanged. It is not necessarily equal to the revenue raised by permit sales because other changes in the economy may raise or lower tax revenue. This formulation is not equivalent to free distribution of permits ( "grandfathering") - that would be represented in a similar fashion in the model but the rebate would be set to the gross revenue raised by permit sales. Other uses of the revenue, such as cutting income taxes or reducing the fiscal deficit, would change some of the results substantially.
} 
independent of the global economy since 1990; and it seems unlikely that international trade and capital flows between this region and the rest of the world will be large enough over the next decade to be a first-order concern. Since the region has relatively little interaction with the rest of the world in the model (as a consequence of the calibration that renders it in equilibrium in the base year), we treat the former Soviet Bloc exogenously in this analysis. (However, we account for income flows from the international sale of permits.) Taking these observations into account, in each of these scenarios, emission reductions in the former Soviet Bloc (encompassing the former Soviet Union and Eastern Europe) are specified exogenously, drawing on mitigation supply curves constructed mainly from the results of the Pacific Northwest National Laboratory's Second Generation Model (SGM). Furthermore, since former Soviet Bloc GHG emissions are expected to remain well below the targets mandated by the Kyoto Protocol, our exogenously specified supply curve for this region includes mitigation of greenhouse gases other than carbon. Thus the analysis assumes a former Soviet Bloc mitigation supply curve with roughly 300 MMTC of "paper tons" (emission allowances that would otherwise remain unused) available in 2010, declining to about 220 MMTC in 2015 and 140 MMTC in 2020, and roughly an additional 220 MMTC available in each year at a cost of less than \$50/MTC (95\$). ${ }^{27}$

Taken together, the G-Cubed baseline and additional simplifying assumptions lead to reduction requirements in 2010 of 526 million metric tons of carbon (MMTC) for the United States, 67 MMTC for Japan, 48 MMTC for Australia, and 461 MMTC for the Other OECD countries; with approximately $27 \%$ of those reductions potentially offset by paper tons from the former Soviet Bloc.

We first present a scenario with unilateral U.S. commitment to meeting its Kyoto target, with no action undertaken by other regions. The remaining four scenarios involve the attainment of Annex I targets specified in the Protocol with:

\footnotetext{
27 The SGM numbers, in turn, are based partly on the results of a joint project between the OECD, the World Bank and the Office of Policy Development at US EPA (see OECD document OECD/GD(97)154 "Environmental Implications of Energy and Transport Subsidies" or Chapter 6 of OECD publication "Reforming Energy and Transport Subsidies." Our estimates ignore a projected 140 MMTCe of other GHG "paper tons" available in 2010.
} 
1. no international permit trading between regions;

2. international permit trading permitted between all Annex I countries;

3. international permit trading permitted within the Other OECD region, and among the other Annex I regions (the U.S., Japan, Australia, and the former Soviet Bloc), but prohibited between the Other OECD region and the rest of the Annex I countries the so-called "double umbrella" or "double bubble;" and

4. global permit trading; that is, the developing regions accept an emissions allocation consistent with their modeled baselines, and allow sales from their permit allocations to Annex I countries.

Graphs illustrating the most important impacts of the Protocol under different assumptions about the extent of international permit trading are provided at the end of the paper. The variables illustrated include regional emission permit prices; emission reductions; international permit sales and purchases; impacts on OPEC oil prices, sales and revenues; changes in international investment and exchange rates; and changes in regions' exports, gross domestic products and gross national products.

Since neither the model's behavioral parameters nor the future values of tax rates, productivity, or other exogenous variables can be known with complete certainty, the results presented here should be regarded as point estimates within a range of possible outcomes. The results do, however, give a clear indication of the mechanisms through which the economy responds to climate change policy. Section 5 will examine the sensitivity of the results to key parameters.

\subsection{Unilateral Emissions Stabilization by the United States}

Key macroeconomic results for the United States in the case of unilateral action by the United States are shown in Table 4. The figures shown are either percent deviations from a "business as usual" baseline or as changes from the baseline in units of 1995 dollars. Results are 
presented for a selection of years, although the model itself is annual.

In order to achieve the Kyoto target, emissions in the United States would need to drop by about 30 percent relative to the baseline in 2010 and by 42 percent in $2020 .^{28}$ The resulting price of carbon emissions permits would be $\$ 80$ per metric ton (95\$) in 2010 rising to $\$ 94$ per ton in $2020 .{ }^{29}$ Most of the drop in emissions comes about through a decline in coal consumption as total energy use drops and the fuel mix shifts toward natural gas, the least carbon-intensive fuel. This is reflected in the industry-level results shown in Table 5: the after-tax price of coal rises by more than 235 percent relative to its baseline level, while coal output declines by 40 percent in 2010 and by 56 percent in 2020. Output of petroleum products falls by $16 \%$ in 2010 and $24 \%$ in 2020; while natural gas output falls by $14 \%$ in 2010 and $23 \%$ in 2020. The crude oil and gas sector is somewhat less affected, suggesting that declines in demand fall disproportionately on imports: domestic output declines by 10 to 20 percent over the period.

Outside the energy industries, prices and output are affected very little. The only noteworthy result is that investment rises by about one percent during the period before the policy is implemented (2000-2007). This stems from the fact that the demand for services increases slightly when households and firms substitute away from energy. As a result, investment by the service industry increases as well, in anticipation of the increase in demand. The increase in investment is financed by an inflow of foreign capital, as aggregate national savings decline slightly. The capital inflow causes the exchange rate to appreciate by about 3.5 percent over that period. The exchange rate appreciation reduces exports, primarily of durable goods, and enables the capital inflow to be reflected in a worsening of the current account.

The international effects of the US policy vary across regions. Most Annex I countries

\footnotetext{
${ }^{28}$ Some of the emissions eliminated within the United States - roughly $10 \%$ in 2010 - are offset by increases in emissions elsewhere. Initially, over half of this "leakage" is due to the fact that other countries buy and burn the oil that the U.S. stops importing. This effect diminishes over time: by 2020 about two-thirds of the leakage is due to higher energy demand resulting from greater economic activity.

29 Throughout the paper carbon will be measured in metric tons (tonnes) and prices will be in 1995 U.S. dollars.
} 
experience mild decreases in GDP on the order of -0.1 percent, mild exchange rate depreciation, and increases in their net investment positions. China's exports rise by 4 to 6 percent in the early years of the policy. Other developing countries receive minor capital inflows after 2010, experience very slight exchange rate appreciation and end up with slightly higher GDPs, but also have lower production and exports of durable goods due to the change in exchange rates.

\subsection{Annex I Targets Met Without International Permit Trading}

In the second scenario, all Annex I regions meet their commitments under the Protocol. Each region is restricted to use of their allocated emissions; the permits can be traded within regions but not from one region to another. ${ }^{30}$ This simulation allows us to measure the heterogeneity of the Annex I regions. Differences in baseline emissions growth, endowments of fossil fuels, reliance on fossil fuels for energy generation and initial fossil fuel prices mean that the regions face substantially different costs of achieving stabilization. This will be reflected in the pattern of permit prices (which will indicate the cost of stabilization at the margin) and GDP losses across regions.

The results for the Annex I policy without international permit trading are shown in Table 6. Key results are presented for 2005, 2010 and 2020 for the four OECD regions in the model (United States, Japan, Australia and other OECD, hereafter referred to as ROECD), as well as China and the less developed countries (LDCs).

The effects of the policy differ substantially across the regions: in 2010, permit prices per metric ton of carbon range from a low of \$87 in the US to a high of \$261 in the ROECD region. These results show that both marginal and average costs of abating carbon emissions differ substantially across countries. Since, by assumption, all regions have access to the same technologies, the differences in permit prices reflect differences in mitigation opportunities: regions which have relatively low baseline carbon emissions per unit of output, and are thus

\footnotetext{
${ }^{30}$ Even though there is no trading between regions, trading is implicitly allowed between the countries within a region. In particular, the "Other OECD" region lumps together the European Union, Canada and New Zealand, so
} 
relatively sparing in their use of fossil fuels, have relatively fewer options for reducing emissions further. The differences among regions stem in part from differences in the fuel mix but also depend on the availability of alternative fuels and the extent to which baseline emissions rise above the stabilization target. Thus Australia, which has relatively few substitution possibilities and a high baseline emission trajectory (due to fairly high population growth and strong productivity growth) finds it costly to reach the 1990 stabilization target. The United States, with low energy prices, a high reliance on coal and abundant natural gas, finds it relatively cheap to change the composition of energy inputs.

The table shows results for both GDP and GNP. The GDP results indicate the extent of international shifts in production but are a poor measure of national welfare. The GNP figures are a better (although far from perfect) welfare measure because GNP reflects the total income accruing to the residents of a country, including net income transfers to and from factors of production located abroad. Savers in countries with high costs of abatement shift some of their financial capital overseas, maintaining rates of return that otherwise would be much lower. The ordering of countries by GNP loss is the same as that by GDP loss but the dispersion of GNP losses is smaller because of the ability of agents to shift capital into higher return activities abroad.

The effect on GDP follows a pattern similar to that of mitigation costs: GDP in 2010 falls slightly in the US and Japan while in Australia and ROECD it falls by 1.8 and 1.5 percent, respectively. Comparing this simulation with the previous one shows that the United States is better off under the Annex I policy than it is when it reduces emissions on its own: in 2010, U.S. GDP 0.4 percent below its baseline value while under the unilateral policy it would have fallen by 0.7 percent. One reason for the lower costs is that U.S. exports are more competitive relative to those from other OECD economies when more countries impose carbon constraints. Another reason for the reduction in GDP loss lies in the fact that the United States has substantially lower marginal costs of abating carbon emissions than other OECD economies. Stabilizing emissions 
requires a smaller price increase in the U.S. than it does in other countries. Also the policy directly reduces rates of return in each economy, and relatively more so in sectors that are relatively carbon intensive. Lower abatement costs in the U.S. mean that rates of return to capital in the U.S. fall less than in other OECD countries. This shift in rates of return induces investors to shift their portfolios toward U.S. assets, leading to an increase in U.S. investment. Thus, production tends to fall less in the U.S. than it does in other OECD economies. The effect is particularly apparent in the years immediately before the policy takes effect: U.S. investment is three percent above baseline in 2005. In addition, the U.S. also benefits from lower world oil prices as Annex I oil demand falls. The boost in investment and lower oil prices both tend to raise energy demand and cause permit prices to rise relative to the unilateral stabilization scenario - from $\$ 80$ to $\$ 87$ in 2010 and from $\$ 94$ to $\$ 101$ in 2020. U.S. income, as measured by GNP, rises slightly in the period before the policy takes effect and then falls by 0.5 to 0.6 percent in 2010-2020.

Examining the effect of the policy on different regions raises a number of interesting results that tend to be ignored in popular discussion of the impacts of emission permit trading. Those regions that have the largest relative abatement costs, such as Australia and ROECD, have large capital outflows because of the fall in the rate of return to capital in high abatement cost countries. ROECD, which faces the greatest cost of stabilizing emissions, has a large capital outflow, accumulating to roughly $\$ 490$ billion (95\$) by 2020. Most of this capital outflow goes to the United States, and some also goes to developing countries, which are not controlling emissions at all. Capital flows to developing countries are limited by adjustment costs, however: it is expensive for a region with a relatively small capital stock to absorb a large flow of new capital. ${ }^{31}$ It is relatively cheap for a large country such as the United States to absorb capital for the same reason: the costs of a given absolute change in a particular capital stock decrease with the size of the stock. Thus, relatively small capital inflows can exhaust arbitrage opportunities in

\footnotetext{
${ }^{31}$ In apparent contradiction to this statement, the results in Table 6 show an apparent net capital outflow from the LDCs rather than a capital inflow. The improvement in the LDCs' net foreign asset position is due to the fact that their real exchange rate appreciation leads to a decrease in the dollar value of their outstanding debt. The decrease in the value of outstanding debt outweighs policy-induced the capital inflow, leading to an apparent capital outflow.
} 
developing economies. This is an important insight because it contradicts the popular perception that greenhouse abatement policies will lead to wholesale migration of industries from developed countries to non-abating developing countries. Our results show this is quite unlikely; moreover, most of the financial capital reallocation is between OECD economies.

Capital flows cause the exchange rates of countries receiving financial capital, such as the Untied States and developing countries, to appreciate, and cause the Japanese and ROECD currencies to depreciate. The dollar appreciates by 25 percent relative to the ROECD currencies, but depreciates by 5 percent relative to the currency of developing countries. The ROECD currency depreciates by 30 percent relative to the developing countries. These changes lead directly to changes in export patterns. By 2010, ROECD exports of durable goods increase by about 6 percent over baseline while U.S. exports of durables fall by 11 percent. At the same time, capital flows cause Australian and ROECD GNP to fall by less slightly than GDP, since these countries' increased foreign investments offset some of the lost income from domestic production.

Overall, the effect of achieving the Kyoto targets is to reduce GDP in countries with high abatement costs, cause an outflow of capital, depreciate their exchange rates and stimulate exports. The effect on low-cost countries is the opposite: capital inflows tend to raise GDP by reducing real interest rates and stimulating domestic demand in the short run, and by raising the capital stock in the medium to long run. Capital inflows also appreciate the exchange rate and diminish exports.

The effect of the Protocol on developing countries is particularly interesting. In the case of the LDCs, the exchange rate appreciation has multiple costs and benefits. Exports become less competitive but imports become cheaper and the dollar value of LDC international debt falls dramatically, leading to a net improvement in the LDCs' net international investment position in spite of significant capital inflows, as mentioned above. LDC gross domestic product rises by three percent in 2010, and gross national product rises by 0.7 percent. Clearly, the absence of commitments under the Kyoto Protocol confers significant benefits to LDCs through 
international policy transmission.

In addition, the decline in Annex I oil demand leads to a 10 percent decline in OPEC oil exports and a 17 percent decline in world oil prices. The decline in oil prices benefits the LDCs, whose increased oil consumption causes an increase in LDC carbon emissions equivalent to approximately 6 percent of Annex I emission reductions. This 6 percent "leakage effect," however, does not translate into increased LDC exports of carbon-intensive durable goods, which are significantly dampened by the impact of capital inflows on LDC exchange rates. Instead it is the region most adversely affected by mitigation policy - ROECD - which experiences an increase in exports. It may seem surprising that export performance should improve in the country most hurt by climate change policy but it is simply the result of consistent international accounting: countries which experience capital outflows must experience trade surpluses, while countries which experience capital inflows must experience trade deficits.

\subsection{Annex I International Permit Trading}

The third scenario is identical to the second except that we allow international trading in emissions permits among Annex I countries. The effect of allowing trading is twofold. First, arbitrage will cause the price of a permit to be equal in all Annex I countries. This will ensure that marginal costs of carbon abatement will be equal across countries and that Annex I emission reductions will be achieved at minimum cost. Countries with relatively low abatement costs will sell permits and abate more than in the previous scenario; countries with high costs will buy permits and undertake less domestic abatement.

In addition, trading makes possible a relaxation of the overall constraint during the 20082012 period because the emissions of one Annex I region, the former Soviet Bloc, are likely to be below the limit specified under the Protocol. The relaxation of the constraint means that actual emission reductions under the Protocol will be considerably lower - perhaps as much as $40 \%$ lower - with international permit trading than without it, at least during the first budget period. 
The particular circumstances of the former Soviet Bloc thus make it difficult to determine the pure gains from permit trading, independent of the relaxation of the constraint. ${ }^{32}$

Results for this scenario are shown in Table 7. In contrast to independent mitigation, international permit trading leads to a uniform permit price throughout the Annex I that rises from about $\$ 61$ per ton in 2010 to $\$ 109$ per ton in 2020. These prices, lower than any OECD region's marginal mitigation cost in the absence of international permit trading, lead to lower increases in fossil fuel prices and considerably lower domestic reductions than in the previous case since reductions can be avoided by purchasing allowances from the former Soviet Bloc. At the 2010 permit price of $\$ 61$ per ton, the former Soviet Bloc sells not only its excess allowances, 293 MMTC, but also reduces emissions to sell an additional 253 MMTC of allowances. Thus the OECD countries purchase nearly 550 MMTC of emission allowances from the former Soviet Bloc rather than undertake domestic reductions, thereby dramatically reducing the cost of meeting their commitments. These purchases particularly benefit ROECD, which uses internationally purchased allowances to meet 72 percent of its obligations and thus achieves a 77 percent reduction in its marginal abatement costs. The United States and Australia use internationally purchased allowances to meet 29 percent and 65 percent of their respective obligations, and benefit from 30 percent and 66 percent reductions in marginal abatement costs. International purchases of former Soviet Bloc allowances amount to nearly \$33 billion (95\$) in 2010 and rise to nearly $\$ 54$ billion by 2020 .

Interestingly, as the regional economies continue to grow after 2010, the demand for emission allowances increases while the former Soviet Bloc's willingness to supply them declines. As a consequence, international permit prices rise continuously after 2010, and by 2020 , prices rise to $\$ 109$ per ton. At this price, the United States becomes a net permit seller, supplying about 83 MMTC of allowances to Japan, Australia and ROECD at a total cost of nearly $\$ 9$ billion, and taking an equivalent quantity of domestic emission reductions in excess of

\footnotetext{
32 Previous analysis using the G-Cubed model indicates that the pure gains from trade are on the order of 20 to 25 percent in the case OECD international permit trading. See McKibbin, Shackleton and Wilcoxen (1998b).
} 
its international commitment.

The economic impacts of the Protocol are generally significantly reduced by both the equalization of marginal mitigation costs and permit prices under an international permit trading regime, as well as by the reduction in overall mitigation due to the sale of former Soviet Bloc's excess allowances. U.S. GDP costs in 2010 are cut from 0.4 percent to 0.2 percent. Japanese GDP costs are cut from 0.6 percent to 0.4 percent, Australia's from 1.8 percent to 0.7 percent, and ROECD's from 1.5 percent to 0.6 percent. Permit trading has little effect on nonparticipants: results for China and the developing countries are very similar to the no-trading case.

Exchange rate changes are similar in sign but generally larger in magnitude than under the no-trading scenario. The Japanese and ROECD currencies, in particular, depreciate somewhat more, while the currency of the developing region has a larger appreciation. This happens because the countries buying permits must ultimately pay for them with additional exports, either immediately or in the future. Thus, the purchasing country's current account must eventually move toward surplus by an amount corresponding to the value of the permits. ${ }^{33}$ The changes in real exchange rates are necessary to accommodate the changes in trade balances.

Permit trading reduces the OECD's overall GNP costs of meeting their commitments under the Kyoto Protocol by about 63 percent in 2010, from $\$ 272$ billion to $\$ 128$ billion, or by $\$ 143$ billion. ${ }^{34}$ On the basis of previous analysis using G-Cubed of OECD permit trading without former Soviet Bloc participation, we estimate that roughly 60 percent of these benefits are due to relaxation of the constraint, while the other 40 percent constitute true gains from trade. If we also take into account the spillover effects on China and the LDCs, the world GNP costs of meeting

\footnotetext{
33 This shifting of resources between economies due to changes in property rights is known in international economics as the "transfer problem," and is the subject of a large literature dating back to the early 1920s when the effects of German war reparations were hotly debated.

${ }^{34}$ We do not provide estimates of GNP effects for the former Soviet Bloc because of the difficulties mentioned previously.
} 
Kyoto commitments is cut by 52 percent from $\$ 241$ billion to $\$ 115$ billion, or by $\$ 125$ billion. These 2010 GNP gains are very unequally dispersed, however: the U.S. ${ }^{35}$ gains only $\$ 14$ billion, and Australia and Japan only $\$ 5$ billion each; while the ROECD region gains $\$ 102$ billion. Chinese and LDC GNPs are almost completely unaffected.

\subsection{The "Double Umbrella"}

In the fourth scenario, the ROECD countries engage in exclusive permit trading and the rest of the Annex I countries engage in permit trading independently of the ROECD countries. Results from this scenario are contained in Table 8. The key difference between this scenario and full Annex I trading is that ROECD no longer buys 327 million tonnes worth of permits from the former Soviet Bloc. As a result, the effects on ROECD look much like the no-trading case and abatement costs in the rest of Annex I fall substantially. Permit prices fall to \$32 in 2010 and \$71 in 2020. The U.S. benefits in two ways: from lower permit prices and also from relatively large capital flows from ROECD to the U.S (because high energy prices reduce returns to capital in ROECD). As a result, U.S. GDP remains at its baseline level in 2010 and falls by only 0.2 percent in 2020 .

It is interesting to note that the ROECD region is slightly better off in the initial years of the double umbrella simulation than under Annex I trading. In 2005, GDP and GNP are slightly higher (that is, they fall slightly less), fuel consumption and investment are both higher, and capital outflows are smaller. The reason for this is somewhat subtle. When the ROECD region adopts carbon controls under either simulation, one effect is to shift some investment to other regions, especially the United States. Under Annex I trading, other countries are also subject to relatively tight carbon controls and are attempting to do the same thing. This causes the U.S. dollar to appreciate substantially, rising by $23 \%$ relative to the ROECD currency in 2005 . Under the double umbrella, however, carbon controls are much looser in regions other than the ROECD so there is less competition to shift capital into the United States. There is less appreciation of

\footnotetext{
${ }^{35}$ The U.S. experiences a small GDP loss from trading in 2010, due to business cycle effects stemming from our assumption that wages adjust slowly: the sharp increase in U.S. energy prices under the trading scenario temporarily
} 
the dollar, which rises by only $16 \%$ relative to the ROECD currency. This makes it less expensive for ROECD investors to convert part of their portfolios to U.S. investments.

This is entirely a short run effect, however. Once the policy is actually in force, the ROECD is hurt more by high abatement costs under the double umbrella than it gains from changes in the terms of trade. By 2010, ROECD GDP and GNP are about $0.8 \%$ below what they would have been under Annex I trading.

\subsection{Global Trading}

In the final scenario, we assume that the non-Annex I developing countries agree to distribute annual quantities of domestic emission permits consistent with their baseline emissions, and to allow these permits to be traded on international markets. ${ }^{36}$ These results are contained in Table 9. The consequence of bringing developing countries into the trading regime is that Annex I countries can purchase emission allowances from owners in developing countries. These owners, in turn, would be willing to sell allowances to Annex I buyers only if the allowance price exceeded the marginal cost to the owners of undertaking emission reductions within the developing countries. The market process would thus lead to least cost reductions on a global scale: emission reductions would be taken wherever they are cheapest, but Annex I countries would pay for them.

Full global trading cuts the permit cost to $\$ 23$ per metric ton of carbon (MTC) in 2010 and \$37 per MTC in 2020, and has minor GDP effects in the Annex I economies, ranging from less than $-0.1 \%$ for the U.S. and Japan to $-0.3 \%$ for Australia and the ROECD. In 2010, the OECD regions achieve 75 to 90 percent of their targets through international purchases of emission allowances. Moreover, since wider availability of emission allowances reduces permit prices, OECD regions are able to purchase international permits at a lower overall cost than in the preceding scenarios: in 2010, international permit sales total $\$ 20$ billion in the global trading

reduces labor demand relative to the no-trading case, leading to a decline in GDP.

${ }^{36}$ As with the Annex I regions, we assume that developing regions sell a fixed number of permits at auction on an 
case, about $60 \%$ of the $\$ 33$ billion value of former Soviet Bloc international permit sales in the Annex I trading case. China provides about 300 MMTC of these allowances, and the other LDCs provide about 195 MMTC; the former Soviet Bloc provides another 410 MMTC. Nearly all of the reductions in China and the LDCs are achieved through reductions in coal use. Thus, one of the crucial effects of expanding from an Annex I trading regime to global trading is to transfer mitigation from oil-related emissions to coal. As a result, oil exporting countries experience only very modest losses in exports and revenues. Finally, global trading eliminates the possibility of carbon leakage.

The reduction in mitigation costs and the equalization of mitigation costs across regions greatly reduces the international macroeconomic effects of the Kyoto Protocol, compared with the previous scenarios. Except for Australia, OECD regions experience GDP and GNP impacts of at most 0.4 percent. Capital flows, exchange rate impacts and trade effects are all considerably lower. Relative to the no-trading case, aggregate OECD GNP costs in 2010 are cut by 78 percent from $\$ 233$ billion to $\$ 51$ billion; and relative to the Annex I trading case, costs are cut by 59 percent. All OECD regions benefit from cost reductions.

Relative to scenarios in which they do not participate in controlling emissions, the developing countries are significantly worse off because they no longer experience significant capital inflows, exchange rate appreciations, reductions in the value of their debt burdens, or lower oil prices. GDP in the LDC region falls by 0.2 percent relative to baseline in 2010 instead of rising as it does under the other simulations. Similarly, China's GDP is also lower under global trading than under the other regimes. In terms of GNP, participating in global trading costs the LDCs \$26 billion in 2010 relative to both the Annex I no-trading and Annex I trading cases. These results suggest that that the Annex I countries may have to use part of their savings (\$73 billion in 2010 from moving from Annex I trading to global trading) simply to induce the developing countries to participate in helping them meet their commitments under the Protocol. 


\section{Alternative Revenue Recycling Mechanisms}

The preceding results are all based on the assumption that countries that undertake commitments to auction emission permits and return the revenues to households in lump-sum payments. We have used the G-Cubed model to perform additional scenarios, using alternative assumptions about the distribution of permits and/or recycling of revenues ${ }^{37}$. While we do not present those results in detail here, we note that the results suggest that alternative revenue recycling mechanisms that serve to increase national savings and/or investment do not have any substantial impact on the marginal costs of meeting targets (under any given set of rules about international permit trading), but can have substantially different international macroeconomic effects. For example, when permit revenues are used to reduce fiscal deficits or increase fiscal surpluses, regions' national savings increase and the global cost of capital falls. Changes in the cost of capital leads to different net international capital flows, exchange rate impacts, and GDP/GNP effects. Extending this insight, we note that the distribution of costs and benefits may be substantially affected if regions pursue differing policies, for example if some regions pursue revenue recycling policies that encourage saving and investment and other regions pursue policies that encourage current consumption. We intend to explore these issues further in continued work with the model.

\section{Sensitivity Analysis}

The results discussed in the preceding sections are conditional on a range of assumptions built into the model. For a model like G-Cubed, which focuses on trade and capital flows, two particularly important sets of parameters are those governing the responsiveness of trade to changes in the prices of traded goods (the "Armington" elasticities) and those governing the ease with which investment can increase industries' stocks of physical capital (capital stock adjustment cost parameters). In this section we examine how changes in these parameters affect both the baseline case and policy scenario results. To keep the discussion manageable, we focus only on the case which the Annex I regions achieve their targets without international permit 
trading. Because it involves the largest international responses to carbon targets, this No-trade case provides the greatest illumination of the sensitivity of the results to parameter assumptions.

There are two sets of Armington trade elasticities in the model, one specifying the elasticity of substitution between domestic and foreign goods, and the other specifying substitutability between alternative sources of foreign goods. In our standard model, we set both of these elasticities to unity. For comparison, we have conducted two groups of sensitivity analyses: one group which we set both elasticities at values of 1.5, 2.0 and 2.5, and another in which we set one of the elasticities at 1.0 and the other at 2.0. The first group of analyses reveals the importance of the overall responsiveness of trade to policy shocks while the second reveals relative importance of the two tiers in determining that responsiveness.

Like the trade elasticities, the capital stock adjustment cost parameters can strongly influence the results. In our standard model, we specify an adjustment cost parameter $\phi$ of 0.4 . In our sensitivity, we reduce the parameter to 0.2 . For an economy with net investment equal to $10 \%$ of the capital stock, this sensitivity implies reducing adjustment costs from $20 \%$ to $10 \%$ of net investment. With these lower adjustment costs it is cheaper to expand a sector's capital stock, all else being equal. Furthermore, for regions with relatively small initial capital stocks, this sensitivity can imply a dramatic reduction in the costs of rapidly expanding the capital stock through foreign investment inflows.

The results for the No-trade scenarios are contained in Table 10 and Table 11, which show, respectively, the effects of varying the parameters on baseline case variables and policy case results. First, higher Armington elasticities permit large baseline capital outflows from developed regions (with relatively modest investment opportunities) to developing regions with greater prospects for productivity growth. This has concomitant effects on the regions' gross domestic and national products, trade, and carbon emissions. Second, this result is influenced by both trade elasticities, although the "top-tier" elasticity of substitution between domestic and

\footnotetext{
${ }^{37}$ See McKibbin and Wilcoxen (1995b) for results on recycling assumptions using an earlier version of the model.
} 
foreign goods plays a somewhat greater role in easing baseline capital flows than that between imports from different regions.

Third, note that lower capital stock adjustment costs make it easier for a region to expand its own domestic capital stock. Although intuition suggests that lower adjustment costs might make it easier to invest in developing countries with small capital stocks, and thus further encourage capital flows to developing regions, the opposite appears to be the case: lower adjustment costs also make it easier for regions to expand their own capital stocks. Thus lower adjustment costs tend to reduce baseline international capital flows rather than increase them, and consequently tend to reduce growth prospects in developing regions as well.

Finally, note that Japanese carbon emissions are significantly higher in baselines with higher trade elasticities. In all the baselines, Japan's real exchange rate depreciates over the next two decades as large quantities of capital flow out of Japan in favor of higher returns in developing countries. With low trade elasticities, the real exchange rate depreciation makes fossil fuels more expensive and tends to moderate energy and carbon emissions. With higher trade elasticities, capital outflows do not have as large an effect on the exchange rate. Since the exchange rate depreciates less, fossil fuel imports are relatively cheaper, which leads to higher Japanese baseline carbon emissions. Higher carbon emissions, finally, require a higher permit price to achieve the Japanese target specified by the Kyoto Protocol.

The policy case sensitivities in Table 11 reveal a number of interesting insights. Perhaps most importantly, larger trade elasticities dramatically reduce the exchange rate adjustment required to generate a capital movement of given magnitude. This is not surprising, since the exchange rate change acts on both imports and exports. As a result, the effect of doubling the Armington elasticity is to cut the exchange rate adjustment required to transfer a given quantity of financial capital by roughly a factor of four. Greater trade responsiveness also reduces the need to relocate physical capital stocks. As a result, the higher the trade elasticities are, the smaller the net foreign asset flows out of regions with high control costs to regions with low or no control costs. 
Because higher trade elasticities moderate both capital flows and exchange rate responses to a given set of carbon emission mitigation policies, they have rather dramatic effects on the distribution of costs across regions. With higher trade elasticities, neither the United States nor the developing countries benefit as much from capital inflows and the resulting improvements in their terms of trade. Consequently, developing countries' GDP and GNP gains from mitigation policies in the Annex I region are dramatically reduced, and U.S. losses are significantly greater. The ROECD region experiences significantly lower declines, and China, which is harmed by Annex I policy when trade elasticities are low, experiences no harm when they are relatively high.

Interestingly, (although we omit the results from the tables to save space) we note that with higher trade elasticities, it is no longer the case that the ROECD region benefits (in the sense of having smaller exchange rate effects and consumption losses) from having the rest of the Annex I form a trading bloc that excludes it. With higher elasticities, and the resulting moderation in exchange rate and capital flow effects, consumption losses are moderated in both the No-Trade and Double Umbrella scenarios, and are almost indistinguishable in the two.

Finally, lower capital stock adjustment costs have the opposite effect of higher trade elasticities. As described above, lower adjustment costs make it easier for a region to expand its own domestic capital stock, and therefore tend to reduce foreign investment in the baseline. However, lowering the adjustment cost parameter has a more profound effect on the investment prospects of developing countries with small capital stocks than it does on the prospects of large developed countries. As a result, in the policy cases in which Annex I regions meet Kyoto commitments, all else being equal, lower adjustment costs lead to larger capital flows from the Annex I regions to the developing regions - with concomitantly larger exchange rate effects and GDP and GNP effects.

It thus appears that the key insights of the G-Cubed model still hold under the sensitivities considered here. It is clear, however, that trade price elasticities and capital stock 
adjustment costs are important determinants of the magnitudes of capital flow and exchange rate responses to a permit trading regime.

\section{Conclusion}

The theoretical appeal of an international permits program is strongest if participating countries have very different marginal costs of abating carbon emissions - in that situation, the potential gains from trade are largest. Our results show that within the Annex I and globally, abatement costs are indeed quite heterogeneous. The marginal cost of meeting Kyoto targets in the "Rest of the OECD" region is triple that of United States; and large quantities of relatively inexpensive emission reductions are available from the former Soviet Bloc and non-Annex I developing regions. These differences in abatement costs are caused by a range of factors including different carbon intensities of energy use, different substitution possibilities and different baseline projections of future carbon emissions. Because of these differences, international trading offers large potential benefits to parties with relatively high mitigation costs.

Our results also highlight the potentially important role of international trade and capital flows in global responses to the Kyoto Protocol, a role not adequately captured in any other modeling system of which we are aware. The results suggest that regions that do not participate in permit trading systems, or that can reduce carbon emissions at relatively low cost, will benefit from significant inflows of international financial capital under any Annex I policy, with or without trading. It appears that the United States is likely to experience capital inflows, exchange rate appreciation and decreased exports. In contrast, the ROECD region, as the highest cost region, will see capital outflows, exchange rate depreciation, increased exports of durables and greater GDP losses. Total flows of capital could accumulate to roughly a half a trillion dollars over the period between 2000 and $2020 .^{38}$ Global participation in a permit trading system would substantially offset these international impacts, but is likely to require additional payments to

\footnotetext{
${ }^{38}$ Compare these magnitudes to the more than trillion dollar decline just in the U.S. net international investment position in the past fifteen years. See the U.S. Government's Survey of Current Business (July 1998).
} 
developing countries to induce them to forgo the benefits that accrue to them if they do not participate.

Because the model is calibrated to a year in which the former Soviet Bloc and China did not participate extensively in global trade, the model effectively assumes that these regions never experience extensive capital inflows or outflows. If these regions become fully participating members of the international trade and finance system by 2010 , then the international trade and capital effects in our scenarios would have to be revised. In particular, the capital that flows to the U.S. and LDCs in these scenarios might be spread to the former Soviet Bloc and China too, with more modest exchange rate and trade balance effects in any given region.

The model's results are also sensitive to assumptions that determine the mitigation cost differences among regions. Different results would be obtained if U.S. domestic mitigation costs were significantly higher but the other regions' permit prices were on the same order of magnitude as in these scenarios (this is the case, for example, in the SGM model from which we derive mitigation cost curves for the former Soviet Bloc). With a smaller relative control cost differential between the U.S. and other countries in the OECD, the magnitude of capital flows to the U.S., and the costs and benefits of those flows, would all be smaller.

Finally, it must be remembered that there are inescapable uncertainties in the values of the model's behavioral parameters and the future values of exogenous variables. As shown by our sensitivity analysis, our results should be interpreted as point estimates in a range of possible outcomes. It is clear, however, that in an increasingly interconnected world in which international financial flows play a crucial role, the impact of greenhouse abatement policy cannot be determined without paying attention to the impact of these policies on the return to capital in different economies. Focusing only on domestic effects would miss a crucial part of the economy's response to climate change policy. To understand the full adjustment process to international greenhouse abatement policy it is essential to model international capital flows explicitly. 


\section{References}

Armington, (1969), "A Theory of Demand for Products Distinguished by Place of Production," International Monetary Fund Staff Papers, vol. 16, pp. 159-76.

Bagnoli, Philip, Warwick J. McKibbin, and Peter J. Wilcoxen (1996) "Future Projections and Structural Change," in N. Nakicenovic, W. D. Nordhaus, R. Richels and F. L. Toth (eds.), Climate Change: Integrating Science, Economics, and Policy, Laxenburg, Austria: International Institute for Applied Systems Analysis, pp. 181-206.

Campbell J. And N. G. Mankiw (1990) "Permanent Income, Current Income and Consumption", Journal of Business and Economic Statistics, 8(2), pp. 265-79.

Feldstein, Martin and Charles Horioka (1980), "Domestic Savings and International Capital Flows," The Economic Journal, 90, pp. 314-29.

Flavin, M. A. (1981), “The Adjustment of Consumption to Changing Expectations about Future Income," Journal of Political Economy, 89, pp. 974-1009.

Gordon, Roger H. and A. Lans Bovenberg (1994), "Why is Capital so Immobile Internationally? Possible Explanations and Implications for Capital Taxation”, mimeo, July.

Goulder, Lawrence H. (1991), "Effects of Carbon Taxes in an Economy with Prior Tax Distortions: An Intertemporal General Equilibrium Analysis for the U.S.," mimeo, June.

Goulder, Lawrence H. and B. Eichengreen (1989), "Savings Promotion, Investment Promotion, and International Competitiveness," in Rob Feenstra (ed.), Trade Policies for International Competitiveness, Chicago: University of Chicago Press.

Gurvich, E., A. Golub, A. Mukhin, M. Uzyakov and M. Ksenofontov (1997), “Greenhouse Gas Impacts of Russian Energy Subsidies" in Reforming Energy and Transport Subsidies: Environmental and Economic Implications, Paris: Organization for Economic Cooperation and Development.

Hall, Robert E. (1978), "Stochastic Implications of the Life-Cycle Hypothesis: Theory and Evidence," Journal of Political Economy, 86, pp. 971-987.

Hayashi, F. (1979) "Tobin's Marginal q and Average q: A Neoclassical Interpretation." Econometrica 50, pp.213-224.

Hayashi, F. (1982) "The Permanent Income Hypothesis: Estimation and Testing by Instrumental Variables. Journal of Political Economy 90(4) pp. 895-916.

Ho, Mun Sing (1989), "The Effects of External Linkages on U.S. Economic Growth: A Dynamic General Equilibrium Analysis", Ph.D. Dissertation, Harvard University. 
Hoel, Michael (1991), "Global Environment Problems: The Effects of Unilateral Actions Taken by One Country", Journal of Environmental Economics and Management, 20(1), pp. 55-70.

Jorgenson, Dale W. and Peter J. Wilcoxen (1991a), "Reducing U.S. Carbon Dioxide Emissions: The Cost of Different Goals," in John R. Moroney, ed., Energy, Growth and the Environment, Greenwich, Connecticut: JAI Press, pp. 125-158.

Kalt, J. P. (1985), "The Impact of Domestic Environmental Regulatory Policies on U.S. International Competitiveness," Discussion Paper E-85-02, Kennedy School of Government, Harvard University.

Kim J. and L. Lau (1994) "The Role of Human Capital in the Economic Growth of the East Asian Newly Industrialized Countries" paper presented at the Asia-Pacific Economic Modelling Conference, Sydney, August.

Lucas, R. E. (1967), "Optimal Investment Policy and the Flexible Accelerator," International Economic Review, 8(1), pp. 78-85.

Manne, Alan S., and Richard G. Richels (1990), "CO2 Emission Limits: An Economic Analysis for the USA," The Energy Journal, 11(2), 51-74.

Manne, Alan S., and Richard G. Richels (1992), Buying Greenhouse Insurance - The Economic Costs of CO2 Emission Limits, Cambridge, MIT Press.

McKibbin Warwick J. and Jeffrey Sachs (1991) Global Linkages: Macroeconomic Interdependence and Cooperation in the World Economy, Brookings Institution, June.

McKibbin, W. J. and Peter J. Wilcoxen (1995a), "Environmental Policy and International Trade" Brookings Discussion Paper in International Economics \#117, The Brookings Institution Washington DC.

McKibbin, Warwick J. and Peter J. Wilcoxen (1995b), "The Theoretical and Empirical Structure of the G-Cubed Model,” Brookings Discussion Paper in International Economics \#118, The Brookings Institution, Washington DC. A revised version of this paper is forthcoming Economic Modelling.

McKibbin, Warwick J., Robert Shackleton and Peter J. Wilcoxen (1998a), "International Trade and Financial Flows in a Carbon-Constrained World", mimeo.

Peck, Stephen and Thomas Teisberg (1990), A Framework for Exploring Cost Effective Carbon Dioxide Control Paths, Palo Alto, CA: Electric Power Research Institute, October.

Treadway, A. (1969), "On Rational Entrepreneurial Behavior and the Demand for Investment," Review of Economic Studies, 3(2), pp. 227-39. 
Uzawa, H. (1969), "Time Preference and the Penrose Effect in a Two Class Model of Economic Growth," Journal of Political Economy, 77, pp. 628-652. 
Table 1: Regions and Sectors in G-Cubed

\begin{tabular}{||l||l||}
\hline \hline Regions & Sectors \\
\hline \hline 1. United States & 1. Electric utilities \\
2. Japan & 2. Gas utilities \\
3. Australia & 3. Petroleum refining \\
4. Other OECD countries & 4. Coal mining \\
5. China & 5. Crude oil and gas extraction \\
6. Former Soviet Bloc & 6. Other mining \\
7. Oil exporting developing countries & 7. Agriculture \\
8. Other developing countries & 8. Forestry and wood products \\
& 9. Durable goods \\
& 10. Nondurables \\
& 11. Transportation \\
\hline
\end{tabular}


Table 2: Production Elasticities

\begin{tabular}{||l||l|l|l|l|l||}
\hline \hline \multirow{2}{*}{ Sector } & \multicolumn{2}{c|}{ Energy } & \multirow{2}{*}{ Materials } & \multicolumn{2}{c||}{ Output } \\
\cline { 2 - 3 } \cline { 5 - 6 } & \multicolumn{1}{|c|}{ Estimated } & Imposed & & \multicolumn{1}{c||}{ Estimated } & Imposed \\
\hline \hline Electricity & 0.200 & & 1.000 & $0.763(0.076)$ & 0.200 \\
\hline Natural Gas & $0.933(0.347)$ & 0.200 & 0.200 & $0.810(0.039)$ & 0.200 \\
\hline Petroleum Refining & 0.200 & & 0.200 & $0.543(0.039)$ & 0.200 \\
\hline Coal Mining & $0.159(0.121)$ & & $0.529(0.018)$ & $1.703(0.038)$ & 0.200 \\
\hline Crude Oil \& Gas & $0.137(0.034)$ & & 0.200 & $0.493(0.031)$ & \\
\hline Other Mining & $1.147(0.136)$ & 0.500 & $2.765(0.028)$ & $1.001(0.315)$ & \\
\hline Agriculture & $0.628(0.051)$ & & $1.732(0.105)$ & $1.283(0.047)$ & \\
\hline Forestry \& Wood & $0.938(0.138)$ & 0.400 & $0.176(0.000)$ & $0.935(0.080)$ & \\
\hline Durables & $0.804(0.058)$ & 0.500 & 0.200 & $0.410(0.019)$ & \\
\hline Nondurables & 1.000 & 0.400 & $0.057(0.000)$ & $1.004(0.012)$ & 0.410 \\
\hline Transportation & 0.200 & & 0.200 & $0.537(0.070)$ & \\
\hline Services & $0.321(0.045)$ & & $3.006(0.073)$ & $0.256(0.027)$ & \\
\hline \hline
\end{tabular}


Table 3: Population Growth Rates

\begin{tabular}{||l||c||}
\hline \hline Region & $\begin{array}{c}\text { Population } \\
\text { Growth Rate }\end{array}$ \\
\hline \hline United States & 0.5 \\
\hline Japan & 0.0 \\
\hline Australia & 0.8 \\
\hline Other OECD & 0.7 \\
\hline China & 1.5 \\
\hline Former Soviet Union & 0.5 \\
\hline Other developing countries & 1.0 \\
\hline
\end{tabular}


Table 4: Aggregate Effects of Unilateral U.S. Action

\begin{tabular}{||l||r|r|r|r||}
\hline & 2005 & 2010 & 2015 & 2020 \\
\hline \hline Permit price (95\$) & -- & $\$ 80$ & $\$ 85$ & $\$ 94$ \\
\hline Carbon emissions & $0.6 \%$ & $-29.6 \%$ & $-35.7 \%$ & $-41.5 \%$ \\
\hline Coal consumption & $0.1 \%$ & $-48.0 \%$ & $-56.2 \%$ & $-64.5 \%$ \\
\hline Oil consumption & $1.0 \%$ & $-18.8 \%$ & $-22.9 \%$ & $-26.7 \%$ \\
\hline Gas consumption & $0.6 \%$ & $-13.9 \%$ & $-19.2 \%$ & $-23.0 \%$ \\
\hline GDP & $0.2 \%$ & $-0.7 \%$ & $-0.8 \%$ & $-0.7 \%$ \\
\hline Consumption & $0.7 \%$ & $-0.4 \%$ & $-0.2 \%$ & $0.1 \%$ \\
\hline Investment & $1.0 \%$ & $-1.1 \%$ & $-0.7 \%$ & $-0.5 \%$ \\
\hline Exchange rate & $3.5 \%$ & $3.5 \%$ & $4.6 \%$ & $5.4 \%$ \\
\hline Exports & $-2.8 \%$ & $-3.3 \%$ & $-4.5 \%$ & $-5.4 \%$ \\
\hline Imports & $-0.7 \%$ & $-3.7 \%$ & $-4.2 \%$ & $-4.7 \%$ \\
\hline Net foreign assets (Bil. 95\$) & $-\$ 77$ & $-\$ 124$ & $-\$ 73$ & $-\$ 21$ \\
\hline GNP & $0.1 \%$ & $-0.7 \%$ & $-0.8 \%$ & $-0.7 \%$ \\
\hline \hline
\end{tabular}


Table 5: Industry Effects of Unilateral U.S. Action

\begin{tabular}{||c||r|r|r|r|r|r||}
\hline \multicolumn{1}{||c||}{} & \multicolumn{2}{c|}{2005} & \multicolumn{2}{c|}{2010} & \multicolumn{2}{c||}{2020} \\
\cline { 2 - 7 } & Price & \multicolumn{1}{c|}{ Qty } & \multicolumn{1}{c|}{ Price } & \multicolumn{1}{c||}{ Qty } & \multicolumn{1}{c||}{ Price } & \multicolumn{1}{c||}{} \\
\hline \hline Energy Industries & & & & & & \\
\hline Electric utilities & $-0.1 \%$ & $0.4 \%$ & $7.2 \%$ & $-6.2 \%$ & $12.6 \%$ & $-9.5 \%$ \\
\hline Gas utilities & $-0.2 \%$ & $0.4 \%$ & $14.3 \%$ & $-13.6 \%$ & $26.0 \%$ & $-22.7 \%$ \\
\hline Petroleum refining & $-0.5 \%$ & $0.4 \%$ & $19.6 \%$ & $-16.2 \%$ & $27.6 \%$ & $-24.4 \%$ \\
\hline Coal mining & $0.1 \%$ & $-0.1 \%$ & $235.4 \%$ & $-40.3 \%$ & $375.6 \%$ & $-56.0 \%$ \\
\hline Oil and gas extraction & $-0.2 \%$ & $0.0 \%$ & $-8.1 \%$ & $-10.4 \%$ & $-7.0 \%$ & $-19.7 \%$ \\
\hline Other Sectors & & & & & & \\
\hline Other mining & $-0.4 \%$ & $-0.3 \%$ & $0.7 \%$ & $-2.6 \%$ & $0.7 \%$ & $-3.3 \%$ \\
\hline Agriculture & $-0.3 \%$ & $0.2 \%$ & $-0.2 \%$ & $-1.2 \%$ & $-0.7 \%$ & $-0.8 \%$ \\
\hline Forestry and wood & $-0.4 \%$ & $0.1 \%$ & $-0.4 \%$ & $-1.2 \%$ & $-0.9 \%$ & $-1.0 \%$ \\
\hline Durable goods & $-0.6 \%$ & $-0.2 \%$ & $-0.6 \%$ & $-1.4 \%$ & $-1.2 \%$ & $-1.4 \%$ \\
\hline Nondurables & $-0.3 \%$ & $0.3 \%$ & $-0.5 \%$ & $-1.0 \%$ & $-0.9 \%$ & $-0.6 \%$ \\
\hline Transportation & $-0.2 \%$ & $0.3 \%$ & $-0.1 \%$ & $-1.6 \%$ & $-0.6 \%$ & $-1.3 \%$ \\
\hline Services & $-0.2 \%$ & $0.4 \%$ & $-0.9 \%$ & $-0.2 \%$ & $-1.4 \%$ & $0.5 \%$ \\
\hline
\end{tabular}


Table 6: Annex I Commitments Without International Permit Trading

\begin{tabular}{|c|c|c|c|c|c|c|}
\hline & 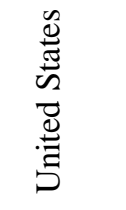 & $\begin{array}{l}\text { : } \\
\text { : } \\
\text { : }\end{array}$ & 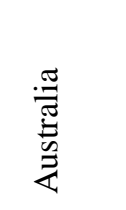 & 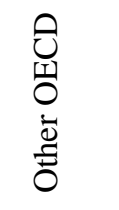 & $\underset{\Xi}{\stackrel{\Xi}{\Xi}}$ & $\dot{U}^{\infty}$ \\
\hline \multicolumn{7}{|l|}{2005} \\
\hline Permit price $(95 \$)$ & -- & -- & -- & -- & -- & -- \\
\hline Carbon emissions & $1.9 \%$ & $-2.4 \%$ & $-0.1 \%$ & $-1.8 \%$ & $-0.9 \%$ & $1.7 \%$ \\
\hline Coal consumption & $0.7 \%$ & $-0.8 \%$ & $0.0 \%$ & $-0.6 \%$ & $-0.8 \%$ & $0.2 \%$ \\
\hline Oil consumption & $3.1 \%$ & $-3.3 \%$ & $-0.1 \%$ & $-2.4 \%$ & $-1.0 \%$ & $2.6 \%$ \\
\hline Gas consumption & $1.9 \%$ & $-0.7 \%$ & $0.0 \%$ & $-1.5 \%$ & $-1.5 \%$ & $1.8 \%$ \\
\hline GDP & $0.4 \%$ & $-0.3 \%$ & $0.1 \%$ & $-0.2 \%$ & $-0.3 \%$ & $0.3 \%$ \\
\hline Investment & $2.9 \%$ & $-0.5 \%$ & $0.6 \%$ & $-2.0 \%$ & $-1.0 \%$ & $2.7 \%$ \\
\hline Exports & $-8.6 \%$ & $3.4 \%$ & $-0.3 \%$ & $7.6 \%$ & $17.2 \%$ & $-21.5 \%$ \\
\hline Exchange rate & $10.8 \%$ & $-6.5 \%$ & $0.7 \%$ & $-12.9 \%$ & $-4.7 \%$ & $15.4 \%$ \\
\hline Net foreign assets (Bil. 95\$) & $-\$ 244$ & $-\$ 49$ & $\$ 16$ & $\$ 184$ & $\$ 20$ & $\$ 78$ \\
\hline GNP & $0.3 \%$ & $-0.3 \%$ & $0.1 \%$ & $0.0 \%$ & $-0.2 \%$ & $0.5 \%$ \\
\hline \multicolumn{7}{|l|}{2010} \\
\hline Permit price $(95 \$)$ & $\$ 87$ & $\$ 112$ & $\$ 181$ & $\$ 261$ & -- & -- \\
\hline Carbon emissions & $-29.6 \%$ & $-20.6 \%$ & $-37.5 \%$ & $-32.7 \%$ & $-0.7 \%$ & $3.3 \%$ \\
\hline Coal consumption & $-51.9 \%$ & $-43.6 \%$ & $-55.1 \%$ & $-49.6 \%$ & $-0.8 \%$ & $0.3 \%$ \\
\hline Oil consumption & $-15.6 \%$ & $-14.2 \%$ & $-18.4 \%$ & $-29.5 \%$ & $-0.4 \%$ & $5.1 \%$ \\
\hline Gas consumption & $-12.6 \%$ & $-4.6 \%$ & $-19.4 \%$ & $-18.2 \%$ & $-1.2 \%$ & $3.4 \%$ \\
\hline GDP & $-0.4 \%$ & $-0.6 \%$ & $-1.8 \%$ & $-1.5 \%$ & $-0.2 \%$ & $0.4 \%$ \\
\hline Investment & $0.8 \%$ & $-1.3 \%$ & $0.2 \%$ & $-3.8 \%$ & $-0.4 \%$ & $2.9 \%$ \\
\hline Exports & $-10.7 \%$ & $1.2 \%$ & $-4.5 \%$ & $5.8 \%$ & $8.1 \%$ & $-25.1 \%$ \\
\hline Exchange rate & $10.5 \%$ & $-5.8 \%$ & $2.1 \%$ & $-13.5 \%$ & $-4.7 \%$ & $15.9 \%$ \\
\hline Net foreign assets (Bil. 95\$) & $-\$ 451$ & $-\$ 55$ & $\$ 29$ & $\$ 370$ & $\$ 34$ & $\$ 141$ \\
\hline GNP & $-0.6 \%$ & $-0.5 \%$ & $-1.6 \%$ & $-1.3 \%$ & $-0.1 \%$ & $0.7 \%$ \\
\hline \multicolumn{7}{|l|}{2020} \\
\hline Permit price $(95 \$)$ & $\$ 101$ & $\$ 162$ & $\$ 230$ & $\$ 315$ & -- & -- \\
\hline Carbon emissions & $-35.7 \%$ & $-27.6 \%$ & $-44.1 \%$ & $-39.1 \%$ & $-0.7 \%$ & $3.1 \%$ \\
\hline Coal consumption & $-59.7 \%$ & $-56.5 \%$ & $-64.7 \%$ & $-58.4 \%$ & $-0.7 \%$ & $0.2 \%$ \\
\hline Oil consumption & $-19.8 \%$ & $-19.6 \%$ & $-21.2 \%$ & $-35.1 \%$ & $-0.4 \%$ & $4.8 \%$ \\
\hline Gas consumption & $-17.9 \%$ & $-6.7 \%$ & $-23.9 \%$ & $-24.0 \%$ & $-1.1 \%$ & $3.4 \%$ \\
\hline GDP & $-0.5 \%$ & $-0.7 \%$ & $-1.8 \%$ & $-1.6 \%$ & $-0.2 \%$ & $0.4 \%$ \\
\hline Investment & $0.9 \%$ & $-1.4 \%$ & $0.3 \%$ & $-3.5 \%$ & $-0.7 \%$ & $2.5 \%$ \\
\hline Exports & $-12.2 \%$ & $1.3 \%$ & $-6.7 \%$ & $4.1 \%$ & $4.7 \%$ & $-20.7 \%$ \\
\hline Exchange rate & $11.0 \%$ & $-7.0 \%$ & $5.0 \%$ & $-13.0 \%$ & $-5.0 \%$ & $15.7 \%$ \\
\hline Net foreign assets (Bil. 95\$) & $-\$ 489$ & $-\$ 104$ & $\$ 48$ & $\$ 490$ & $\$ 43$ & $\$ 184$ \\
\hline GNP & $-0.7 \%$ & $-0.7 \%$ & $-1.5 \%$ & $-1.3 \%$ & $-0.1 \%$ & $0.7 \%$ \\
\hline
\end{tabular}


Table 7: Annex I Commitments With International Permit Trading

\begin{tabular}{|c|c|c|c|c|c|c|}
\hline & 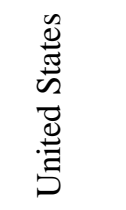 & 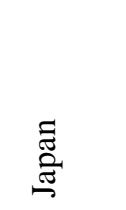 & 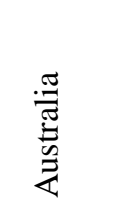 & 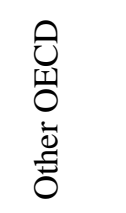 & $\underset{\Xi}{\stackrel{\Xi}{\Xi}}$ & $\bigcup_{\beth}^{\infty}$ \\
\hline \multicolumn{7}{|l|}{2005} \\
\hline Permit price $(95 \$)$ & -- & -- & -- & -- & -- & -- \\
\hline Annual permit sales (Bil. 95\$) & -- & -- & -- & -- & -- & -- \\
\hline Carbon emissions & $1.4 \%$ & $-2.7 \%$ & $-0.3 \%$ & $-2.1 \%$ & $-0.6 \%$ & $1.8 \%$ \\
\hline Coal consumption & $0.6 \%$ & $-1.0 \%$ & $-0.3 \%$ & $-0.6 \%$ & $-0.6 \%$ & $0.2 \%$ \\
\hline Oil consumption & $2.3 \%$ & $-3.7 \%$ & $-0.7 \%$ & $-2.9 \%$ & $-0.8 \%$ & $2.7 \%$ \\
\hline Gas consumption & $1.5 \%$ & $-0.7 \%$ & $-0.8 \%$ & $-1.7 \%$ & $-1.2 \%$ & $1.9 \%$ \\
\hline GDP & $0.3 \%$ & $-0.2 \%$ & $0.0 \%$ & $-0.2 \%$ & $-0.2 \%$ & $0.3 \%$ \\
\hline Investment & $2.3 \%$ & $-0.6 \%$ & $-0.3 \%$ & $-2.2 \%$ & $-0.6 \%$ & $3.0 \%$ \\
\hline Exports & $-6.9 \%$ & $3.6 \%$ & $1.1 \%$ & $8.9 \%$ & $11.5 \%$ & $-22.8 \%$ \\
\hline Exchange rate & $8.9 \%$ & $-7.1 \%$ & $-0.6 \%$ & $-14.4 \%$ & $-2.4 \%$ & $16.6 \%$ \\
\hline Net foreign assets (Bil. 95\$) & $-\$ 139$ & $-\$ 28$ & $\$ 22$ & $\$ 242$ & $\$ 16$ & $\$ 67$ \\
\hline GNP & $0.2 \%$ & $-0.2 \%$ & $0.0 \%$ & $-0.1 \%$ & $-0.2 \%$ & $0.5 \%$ \\
\hline \multicolumn{7}{|l|}{2010} \\
\hline Permit price $(95 \$)$ & $\$ 61$ & $\$ 61$ & $\$ 61$ & $\$ 61$ & -- & -- \\
\hline Annual permit sales (Bil. 95\$) & $-\$ 9.4$ & $-\$ 1.5$ & $-\$ 1.9$ & $-\$ 20.3$ & -- & -- \\
\hline Carbon emissions & $-20.9 \%$ & $-13.0 \%$ & $-13.0 \%$ & $-9.1 \%$ & $-0.5 \%$ & $2.6 \%$ \\
\hline Coal consumption & $-36.0 \%$ & $-24.2 \%$ & $-18.7 \%$ & $-12.1 \%$ & $-0.5 \%$ & $0.4 \%$ \\
\hline Oil consumption & $-11.8 \%$ & $-10.4 \%$ & $-6.7 \%$ & $-9.0 \%$ & $-0.4 \%$ & $4.0 \%$ \\
\hline Gas consumption & $-8.8 \%$ & $-2.9 \%$ & $-6.8 \%$ & $-5.6 \%$ & $-0.7 \%$ & $2.9 \%$ \\
\hline GDP & $-0.2 \%$ & $-0.4 \%$ & $-0.7 \%$ & $-0.6 \%$ & $-0.1 \%$ & $0.4 \%$ \\
\hline Investment & $0.8 \%$ & $-1.0 \%$ & $-0.3 \%$ & $-2.4 \%$ & $-0.3 \%$ & $2.8 \%$ \\
\hline Exports & $-7.6 \%$ & $2.5 \%$ & $-0.8 \%$ & $8.0 \%$ & $5.7 \%$ & $-23.7 \%$ \\
\hline Exchange rate & $8.5 \%$ & $-6.7 \%$ & $-0.4 \%$ & $-14.7 \%$ & $-2.1 \%$ & $17.5 \%$ \\
\hline Net foreign assets (Bil. 95\$) & $-\$ 304$ & $-\$ 12$ & $\$ 36$ & $\$ 476$ & $\$ 29$ & $\$ 121$ \\
\hline GNP & $-0.5 \%$ & $-0.4 \%$ & $-0.8 \%$ & $-0.6 \%$ & $-0.1 \%$ & $0.7 \%$ \\
\hline \multicolumn{7}{|l|}{2020} \\
\hline Permit price $(95 \$)$ & $\$ 109$ & $\$ 109$ & $\$ 109$ & $\$ 109$ & -- & -- \\
\hline Annual permit sales (Bil. 95\$) & $\$ 9.0$ & $-\$ 4.4$ & $-\$ 4.6$ & $-\$ 53.7$ & -- & -- \\
\hline Carbon emissions & $-33.3 \%$ & $-18.6 \%$ & $-18.4 \%$ & $-13.0 \%$ & $-0.4 \%$ & $2.7 \%$ \\
\hline Coal consumption & $-54.5 \%$ & $-35.4 \%$ & $-26.8 \%$ & $-17.8 \%$ & $-0.4 \%$ & $0.4 \%$ \\
\hline Oil consumption & $-19.9 \%$ & $-14.3 \%$ & $-9.2 \%$ & $-12.3 \%$ & $-0.3 \%$ & $4.2 \%$ \\
\hline Gas consumption & $-16.6 \%$ & $-4.5 \%$ & $-10.0 \%$ & $-8.3 \%$ & $-0.6 \%$ & $3.1 \%$ \\
\hline GDP & $-0.5 \%$ & $-0.5 \%$ & $-0.9 \%$ & $-0.7 \%$ & $-0.1 \%$ & $0.5 \%$ \\
\hline Investment & $0.5 \%$ & $-1.1 \%$ & $-0.2 \%$ & $-2.4 \%$ & $-0.4 \%$ & $2.7 \%$ \\
\hline Exports & $-9.1 \%$ & $2.2 \%$ & $-1.9 \%$ & $7.3 \%$ & $2.7 \%$ & $-20.2 \%$ \\
\hline Exchange rate & $9.1 \%$ & $-7.1 \%$ & $0.5 \%$ & $-15.0 \%$ & $-2.1 \%$ & $17.9 \%$ \\
\hline Net foreign assets (Bil. 95\$) & $-\$ 390$ & $-\$ 22$ & $\$ 47$ & $\$ 614$ & $\$ 40$ & $\$ 165$ \\
\hline GNP & $-0.7 \%$ & $-0.5 \%$ & $-1.1 \%$ & $-0.7 \%$ & $0.0 \%$ & $0.7 \%$ \\
\hline
\end{tabular}


Table 8: Annex I Commitments With "Double Umbrella"

\begin{tabular}{|c|c|c|c|c|c|c|}
\hline & 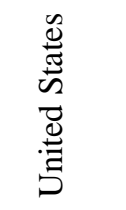 & 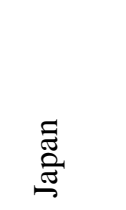 & 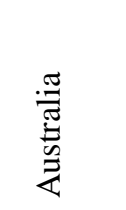 & 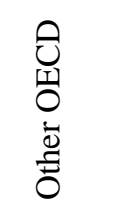 & 节 & 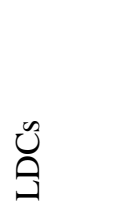 \\
\hline \multicolumn{7}{|l|}{2005} \\
\hline Permit price $(95 \$)$ & -- & -- & -- & -- & -- & -- \\
\hline Annual permit sales (Bil. 95\$) & $\begin{array}{ll}-- \\
\end{array}$ & -- & -- & -- & -- & -- \\
\hline Carbon emissions & $1.2 \%$ & $-2.0 \%$ & $-0.3 \%$ & $-1.3 \%$ & $-0.5 \%$ & $1.1 \%$ \\
\hline Coal consumption & $0.5 \%$ & $-0.7 \%$ & $0.0 \%$ & $-0.5 \%$ & $-0.5 \%$ & $0.1 \%$ \\
\hline Oil consumption & $1.9 \%$ & $-2.9 \%$ & $-0.7 \%$ & $-1.8 \%$ & $-0.6 \%$ & $1.8 \%$ \\
\hline Gas consumption & $1.2 \%$ & $-0.6 \%$ & $-0.4 \%$ & $-1.1 \%$ & $-0.9 \%$ & $1.3 \%$ \\
\hline GDP & $0.3 \%$ & $-0.2 \%$ & $-0.1 \%$ & $-0.1 \%$ & $-0.2 \%$ & $0.2 \%$ \\
\hline Investment & $1.8 \%$ & $-0.5 \%$ & $-0.5 \%$ & $-1.4 \%$ & $-0.6 \%$ & $1.9 \%$ \\
\hline Exports & $-5.4 \%$ & $3.2 \%$ & $1.1 \%$ & $5.3 \%$ & $10.5 \%$ & $-14.8 \%$ \\
\hline Exchange rate & $6.9 \%$ & $-5.7 \%$ & $-1.3 \%$ & $-9.1 \%$ & $-2.7 \%$ & $10.5 \%$ \\
\hline Net foreign assets (Bil. 95\$) & $-\$ 137$ & $-\$ 18$ & $\$ 20$ & $\$ 139$ & $\$ 13$ & $\$ 53$ \\
\hline GNP & $0.2 \%$ & $-0.2 \%$ & $0.0 \%$ & $0.0 \%$ & $-0.1 \%$ & $0.3 \%$ \\
\hline \multicolumn{7}{|l|}{2010} \\
\hline Permit price $(95 \$)$ & $\$ 32$ & $\$ 32$ & $\$ 32$ & $\$ 263$ & -- & -- \\
\hline Annual permit sales (Bil. 95\$) & $-\$ 11.4$ & $-\$ 1.6$ & $-\$ 1.3$ & -- & -- & -- \\
\hline Carbon emissions & $-9.2 \%$ & $-5.7 \%$ & $-6.7 \%$ & $-32.7 \%$ & $-0.4 \%$ & $2.2 \%$ \\
\hline Coal consumption & $-18.2 \%$ & $-11.9 \%$ & $-9.6 \%$ & $-49.8 \%$ & $-0.4 \%$ & $0.3 \%$ \\
\hline Oil consumption & $-3.3 \%$ & $-4.1 \%$ & $-3.2 \%$ & $-29.5 \%$ & $-0.3 \%$ & $3.4 \%$ \\
\hline Gas consumption & $-3.1 \%$ & $-1.5 \%$ & $-3.6 \%$ & $-18.1 \%$ & $-0.7 \%$ & $2.2 \%$ \\
\hline GDP & $0.0 \%$ & $-0.3 \%$ & $-0.4 \%$ & $-1.4 \%$ & $-0.1 \%$ & $0.3 \%$ \\
\hline Investment & $1.3 \%$ & $-0.6 \%$ & $-0.2 \%$ & $-3.4 \%$ & $-0.2 \%$ & $2.0 \%$ \\
\hline Exports & $-6.9 \%$ & $1.9 \%$ & $-0.5 \%$ & $4.3 \%$ & $5.3 \%$ & $-16.7 \%$ \\
\hline Exchange rate & $6.6 \%$ & $-5.4 \%$ & $-1.3 \%$ & $-9.3 \%$ & $-2.5 \%$ & $11.0 \%$ \\
\hline Net foreign assets (Bil. 95\$) & $-\$ 281$ & $-\$ 1$ & $\$ 32$ & $\$ 298$ & $\$ 23$ & $\$ 103$ \\
\hline GNP & $-0.2 \%$ & $-0.2 \%$ & $-0.5 \%$ & $-1.3 \%$ & $-0.1 \%$ & $0.5 \%$ \\
\hline \multicolumn{7}{|l|}{2020} \\
\hline Permit price $(95 \$)$ & $\$ 71$ & $\$ 71$ & $\$ 71$ & $\$ 318$ & -- & -- \\
\hline Annual permit sales (Bil. 95\$) & $-\$ 19.8$ & $-\$ 5.7$ & $-\$ 3.9$ & -- & -- & -- \\
\hline Carbon emissions & $-18.6 \%$ & $-10.4 \%$ & $-11.0 \%$ & $-39.9 \%$ & $-0.3 \%$ & $2.2 \%$ \\
\hline Coal consumption & $-32.3 \%$ & $-21.3 \%$ & $-16.1 \%$ & $-60.0 \%$ & $-0.4 \%$ & $0.3 \%$ \\
\hline Oil consumption & $-9.6 \%$ & $-7.3 \%$ & $-5.3 \%$ & $-35.7 \%$ & $-0.2 \%$ & $3.5 \%$ \\
\hline Gas consumption & $-8.5 \%$ & $-2.6 \%$ & $-6.1 \%$ & $-24.2 \%$ & $-0.4 \%$ & $2.4 \%$ \\
\hline GDP & $-0.2 \%$ & $-0.3 \%$ & $-0.6 \%$ & $-1.5 \%$ & $-0.1 \%$ & $0.3 \%$ \\
\hline Investment & $0.7 \%$ & $-0.8 \%$ & $-0.3 \%$ & $-3.1 \%$ & $-0.3 \%$ & $1.8 \%$ \\
\hline Exports & $-7.7 \%$ & $1.7 \%$ & $-1.2 \%$ & $2.4 \%$ & $2.7 \%$ & $-14.5 \%$ \\
\hline Exchange rate & $6.2 \%$ & $-6.0 \%$ & $-1.3 \%$ & $-8.4 \%$ & $-2.8 \%$ & $10.7 \%$ \\
\hline Net foreign assets (Bil. 95\$) & $-\$ 363$ & $-\$ 15$ & $\$ 41$ & $\$ 440$ & $\$ 29$ & $\$ 141$ \\
\hline GNP & $-0.5 \%$ & $-0.3 \%$ & $-0.7 \%$ & $-1.3 \%$ & $0.0 \%$ & $0.5 \%$ \\
\hline
\end{tabular}


Table 9: Annex I Commitments With Global Permit Trading

\begin{tabular}{|c|c|c|c|c|c|c|}
\hline & 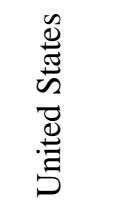 & $\begin{array}{l}\text { : } \\
\text { స్త్ }\end{array}$ & 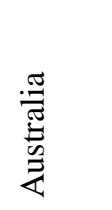 & 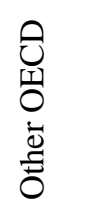 & : & $\bigcup_{\beth}^{\infty}$ \\
\hline \multicolumn{7}{|l|}{2005} \\
\hline Permit price $(95 \$)$ & -- & -- & -- & -- & -- & -- \\
\hline Annual permit sales (Bil. 95\$) & -- & -- & -- & -- & -- & -- \\
\hline Carbon emissions & $0.6 \%$ & $-1.2 \%$ & $-0.1 \%$ & $-0.9 \%$ & $0.9 \%$ & $0.8 \%$ \\
\hline Coal consumption & $0.2 \%$ & $-0.3 \%$ & $0.0 \%$ & $-0.3 \%$ & $0.9 \%$ & $0.4 \%$ \\
\hline Oil consumption & $1.0 \%$ & $-1.7 \%$ & $-0.4 \%$ & $-1.3 \%$ & $1.2 \%$ & $1.1 \%$ \\
\hline Gas consumption & $0.7 \%$ & $-0.3 \%$ & $-0.4 \%$ & $-0.8 \%$ & $1.8 \%$ & $0.7 \%$ \\
\hline GDP & $0.1 \%$ & $-0.1 \%$ & $0.0 \%$ & $-0.1 \%$ & $0.4 \%$ & $0.1 \%$ \\
\hline Investment & $1.0 \%$ & $-0.2 \%$ & $-0.3 \%$ & $-1.0 \%$ & $2.4 \%$ & $1.1 \%$ \\
\hline Exports & $-2.9 \%$ & $1.5 \%$ & $1.0 \%$ & $4.1 \%$ & $-27.2 \%$ & $-8.7 \%$ \\
\hline Exchange rate & $3.7 \%$ & $-3.1 \%$ & $-0.6 \%$ & $-7.0 \%$ & $12.4 \%$ & $6.1 \%$ \\
\hline Net foreign assets (Bil. 95\$) & $-\$ 54$ & $-\$ 8$ & $\$ 12$ & $\$ 106$ & $-\$ 38$ & $\$ 25$ \\
\hline GNP & $0.1 \%$ & $-0.1 \%$ & $0.0 \%$ & $0.0 \%$ & $0.3 \%$ & $0.2 \%$ \\
\hline \multicolumn{7}{|l|}{2010} \\
\hline Permit price $(95 \$)$ & $\$ 23$ & $\$ 23$ & $\$ 23$ & $\$ 23$ & $\$ 23$ & $\$ 23$ \\
\hline Annual permit sales (Bil. 95\$) & $-\$ 8.9$ & $-\$ 1.2$ & $-\$ 1.0$ & $-\$ 9.3$ & $\$ 7.0$ & $\$ 4.5$ \\
\hline Carbon emissions & $-7.4 \%$ & $-4.2 \%$ & $-4.9 \%$ & $-3.4 \%$ & $-19.1 \%$ & $-7.9 \%$ \\
\hline Coal consumption & $-13.3 \%$ & $-8.9 \%$ & $-7.0 \%$ & $-4.5 \%$ & $-22.0 \%$ & $-13.3 \%$ \\
\hline Oil consumption & $-3.6 \%$ & $-2.8 \%$ & $-2.4 \%$ & $-3.3 \%$ & $-3.3 \%$ & $-5.6 \%$ \\
\hline Gas consumption & $-3.0 \%$ & $-1.0 \%$ & $-2.9 \%$ & $-2.2 \%$ & $-10.4 \%$ & $-2.0 \%$ \\
\hline GDP & $-0.1 \%$ & $-0.1 \%$ & $-0.3 \%$ & $-0.3 \%$ & $-0.6 \%$ & $-0.2 \%$ \\
\hline Investment & $0.4 \%$ & $-0.3 \%$ & $-0.2 \%$ & $-1.0 \%$ & $0.6 \%$ & $0.1 \%$ \\
\hline Exports & $-3.4 \%$ & $0.8 \%$ & $-0.3 \%$ & $3.6 \%$ & $-22.6 \%$ & $-9.7 \%$ \\
\hline Exchange rate & $3.6 \%$ & $-2.8 \%$ & $-0.6 \%$ & $-7.2 \%$ & $10.9 \%$ & $6.5 \%$ \\
\hline Net foreign assets (Bil. 95\$) & $-\$ 115$ & $-\$ 2$ & $\$ 20$ & $\$ 208$ & $-\$ 71$ & $\$ 51$ \\
\hline GNP & $-0.2 \%$ & $-0.1 \%$ & $-0.4 \%$ & $-0.2 \%$ & $-0.4 \%$ & $0.0 \%$ \\
\hline \multicolumn{7}{|l|}{2020} \\
\hline Permit price $(95 \$)$ & $\$ 37$ & $\$ 37$ & $\$ 37$ & $\$ 37$ & $\$ 37$ & $\$ 37$ \\
\hline Annual permit sales (Bil. 95\$) & $-\$ 21.1$ & $-\$ 3.9$ & $-\$ 2.5$ & $-\$ 25.2$ & $\$ 24.3$ & $\$ 17.1$ \\
\hline Carbon emissions & $-11.4 \%$ & $-6.1 \%$ & $-6.5 \%$ & $-4.6 \%$ & $-24.9 \%$ & $-11.1 \%$ \\
\hline Coal consumption & $-19.2 \%$ & $-12.8 \%$ & $-9.7 \%$ & $-6.3 \%$ & $-28.7 \%$ & $-17.8 \%$ \\
\hline Oil consumption & $-6.2 \%$ & $-4.2 \%$ & $-3.1 \%$ & $-4.4 \%$ & $-4.9 \%$ & $-8.2 \%$ \\
\hline Gas consumption & $-5.5 \%$ & $-1.5 \%$ & $-3.5 \%$ & $-3.0 \%$ & $-13.5 \%$ & $-3.6 \%$ \\
\hline GDP & $-0.1 \%$ & $-0.2 \%$ & $-0.3 \%$ & $-0.3 \%$ & $-0.7 \%$ & $-0.3 \%$ \\
\hline Investment & $0.3 \%$ & $-0.4 \%$ & $-0.1 \%$ & $-1.0 \%$ & $0.3 \%$ & $0.0 \%$ \\
\hline Exports & $-3.9 \%$ & $0.7 \%$ & $-0.7 \%$ & $3.3 \%$ & $-20.0 \%$ & $-9.0 \%$ \\
\hline Exchange rate & $3.6 \%$ & $-3.4 \%$ & $-0.4 \%$ & $-7.5 \%$ & $15.0 \%$ & $7.0 \%$ \\
\hline Net foreign assets (Bil. 95\$) & $-\$ 155$ & $-\$ 13$ & $\$ 25$ & $\$ 263$ & $-\$ 66$ & $\$ 78$ \\
\hline GNP & $-0.3 \%$ & $-0.2 \%$ & $-0.4 \%$ & $-0.3 \%$ & $-0.1 \%$ & $0.0 \%$ \\
\hline
\end{tabular}


Table 10: The Effect of Parameter Settings on Base Case Variables for 2010

\begin{tabular}{|c|c|c|c|c|c|c|c|}
\hline & 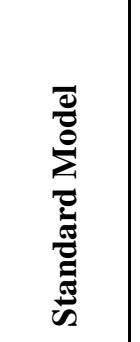 & 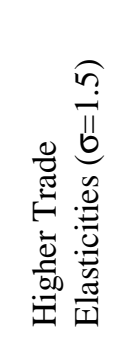 & 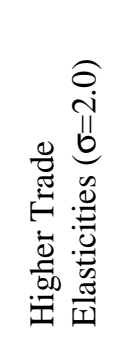 & 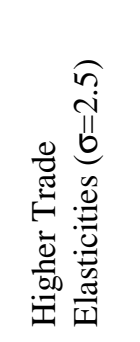 & 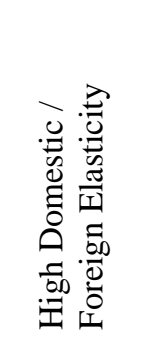 & 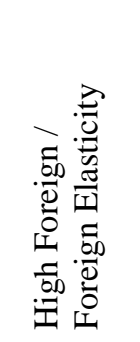 & 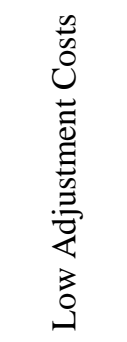 \\
\hline \begin{tabular}{|c|} 
Parameter Settings \\
Domestic/Foreign Elasticity \\
Foreign/Foreign Elasticity \\
Adjustment Costs \\
\end{tabular} & $\begin{array}{r}1.0 \\
1.0 \\
20 \% \\
\end{array}$ & $\begin{array}{r}1.5 \\
1.5 \\
20 \% \\
\end{array}$ & $\begin{array}{r}2.0 \\
2.0 \\
20 \% \\
\end{array}$ & $\begin{array}{r}2.5 \\
2.5 \\
20 \% \\
\end{array}$ & $\begin{array}{r}2.0 \\
1.0 \\
20 \% \\
\end{array}$ & $\begin{array}{r}1.0 \\
2.0 \\
20 \% \\
\end{array}$ & $\begin{array}{r}1.0 \\
1.0 \\
10 \% \\
\end{array}$ \\
\hline \begin{tabular}{|l|} 
United States \\
Carbon Emissions (Mil. tonnes) \\
GDP (Bil. 95 \$) \\
GNP (Bil. $95 \$$ ) \\
Net Investment Position (Bil. $95 \$$ ) \\
\end{tabular} & $\begin{array}{r}1780 \\
\$ 9,502 \\
\$ 9,576 \\
\$ 1,133 \\
\end{array}$ & $\begin{array}{r}1771 \\
\$ 9,479 \\
\$ 9,606 \\
\$ 2,250 \\
\end{array}$ & $\begin{array}{r}1776 \\
\$ 9,470 \\
\$ 9,625 \\
\$ 2,869 \\
\end{array}$ & $\begin{array}{r}1783 \\
\$ 9,466 \\
\$ 9,639 \\
\$ 3,261 \\
\end{array}$ & $\begin{array}{r}1763 \\
\$ 9,468 \\
\$ 9,602 \\
\$ 2,394 \\
\end{array}$ & $\begin{array}{r}1782 \\
\$ 9,493 \\
\$ 9,608 \\
\$ 2,010 \\
\end{array}$ & $\begin{array}{r}1816 \\
\$ 9,559 \\
\$ 9,610 \\
\$ 670\end{array}$ \\
\hline \begin{tabular}{|l} 
Australia \\
Carbon Emissions (Mil. tonnes) \\
GDP (Bil. 95 \$) \\
GNP (Bil. 95 \$) \\
Net Investment Position (Bil. $95 \$$ ) \\
\end{tabular} & $\begin{array}{r}128 \\
\$ 592 \\
\$ 578 \\
(\$ 265) \\
\end{array}$ & $\begin{array}{r}129 \\
\$ 590 \\
\$ 574 \\
(\$ 314) \\
\end{array}$ & $\begin{array}{r}130 \\
\$ 590 \\
\$ 572 \\
(\$ 349) \\
\end{array}$ & $\begin{array}{r}131 \\
\$ 591 \\
\$ 572 \\
(\$ 379) \\
\end{array}$ & $\begin{array}{r}129 \\
\$ 590 \\
\$ 573 \\
(\$ 331) \\
\end{array}$ & $\begin{array}{r}129 \\
\$ 590 \\
\$ 574 \\
(\$ 293) \\
\end{array}$ & $\begin{array}{r}128 \\
\$ 590 \\
\$ 576 \\
(\$ 262) \\
\end{array}$ \\
\hline \begin{tabular}{|l|} 
Japan \\
Carbon Emissions (Mil. tonnes) \\
GDP (Bil. 95 \$) \\
GNP (Bil. $95 \$$ ) \\
Net Investment Position (Bil. $95 \$$ ) \\
\end{tabular} & $\begin{array}{r}325 \\
\$ 4,675 \\
\$ 4,775 \\
\$ 2,377 \\
\end{array}$ & $\begin{array}{r}339 \\
\$ 4,787 \\
\$ 4,904 \\
\$ 2,610 \\
\end{array}$ & $\begin{array}{r}346 \\
\$ 4,816 \\
\$ 4,941 \\
\$ 2,727 \\
\end{array}$ & $\begin{array}{r}350 \\
\$ 4,827 \\
\$ 4,959 \\
\$ 2,810 \\
\end{array}$ & $\begin{array}{r}339 \\
\$ 4,789 \\
\$ 4,916 \\
\$ 2,808 \\
\end{array}$ & $\begin{array}{r}338 \\
\$ 4,780 \\
\$ 4,889 \\
\$ 2,444 \\
\end{array}$ & $\begin{array}{r}340 \\
\$ 4,805 \\
\$ 4,903 \\
\$ 2,154 \\
\end{array}$ \\
\hline \begin{tabular}{|l|} 
Other OECD \\
Carbon Emissions (Mil. tonnes) \\
GDP (Bil. $95 \$$ ) \\
GNP (Bil. 95 \$) \\
Net Investment Position (Bil. $95 \$$ ) \\
\end{tabular} & $\begin{array}{r}1411 \\
\$ 12,973 \\
\$ 13,044 \\
\$ 1,180 \\
\end{array}$ & $\begin{array}{r}1369 \\
\$ 12,874 \\
\$ 13,020 \\
\$ 2,754 \\
\end{array}$ & $\begin{array}{r}1362 \\
\$ 12,846 \\
\$ 13,033 \\
\$ 3,612 \\
\end{array}$ & $\begin{array}{r}1358 \\
\$ 12,832 \\
\$ 13,045 \\
\$ 4,160 \\
\end{array}$ & $\begin{array}{r}1369 \\
\$ 12,872 \\
\$ 13,012 \\
\$ 2,680 \\
\end{array}$ & $\begin{array}{r}1367 \\
\$ 12,878 \\
\$ 13,031 \\
\$ 2,851 \\
\end{array}$ & $\begin{array}{r}1434 \\
\$ 12,997 \\
\$ 13,039 \\
\$ 788 \\
\end{array}$ \\
\hline \begin{tabular}{|l|} 
China \\
Carbon Emissions (Mil. tonnes) \\
GDP (Bil. 95 \$) \\
GNP (Bil. $95 \$$ ) \\
Net Investment Position (Bil. $95 \$$ ) \\
\end{tabular} & $\begin{array}{r}1589 \\
\$ 1,673 \\
\$ 1,567 \\
-\$ 2,107 \\
\end{array}$ & $\begin{array}{r}1574 \\
\$ 1,678 \\
\$ 1,521 \\
-\$ 3,150 \\
\end{array}$ & $\begin{array}{r}1555 \\
\$ 1,678 \\
\$ 1,493 \\
-\$ 3,699 \\
\end{array}$ & $\begin{array}{r}1541 \\
\$ 1,678 \\
\$ 1,476 \\
-\$ 4,039 \\
\end{array}$ & $\begin{array}{r}1538 \\
\$ 1,676 \\
\$ 1,519 \\
-\$ 3,144 \\
\end{array}$ & $\begin{array}{r}1607 \\
\$ 1,680 \\
\$ 1,525 \\
-\$ 3,107 \\
\end{array}$ & $\begin{array}{r}1436 \\
\$ 1,617 \\
\$ 1,541 \\
-\$ 1,485 \\
\end{array}$ \\
\hline \begin{tabular}{|l|} 
LDCs \\
Carbon Emissions (Mil. tonnes) \\
GDP (Bil. 95 \$) \\
GNP (Bil. 95 \$) \\
Net Investment Position (Bil. 95 \$) \\
\end{tabular} & $\begin{array}{r}2392 \\
\$ 4,451 \\
\$ 4,245 \\
-\$ 4,384 \\
\end{array}$ & $\begin{array}{r}2480 \\
\$ 4,492 \\
\$ 4,188 \\
-\$ 6,458 \\
\end{array}$ & $\begin{array}{r}2490 \\
\$ 4,504 \\
\$ 4,139 \\
-\$ 7,644\end{array}$ & $\begin{array}{r}2492 \\
\$ 4,510 \\
\$ 4,104 \\
-\$ 8,422\end{array}$ & $\begin{array}{r}2496 \\
\$ 4,514 \\
\$ 4,198 \\
-\$ 6,692\end{array}$ & $\begin{array}{r}2465 \\
\$ 4,473 \\
\$ 4,181 \\
-\$ 6,194\end{array}$ & $\begin{array}{r}2270 \\
\$ 4,357 \\
\$ 4,166 \\
-\$ 3,958\end{array}$ \\
\hline
\end{tabular}


Table 11: The Effect of Parameter Settings on No-Trade Results for 2010

\begin{tabular}{|c|c|c|c|c|c|c|c|}
\hline & 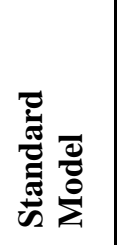 & 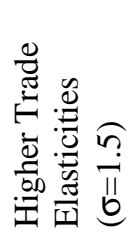 & 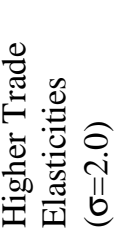 & 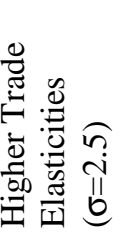 & 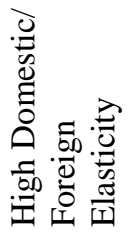 & 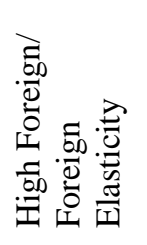 & 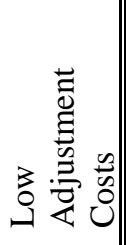 \\
\hline \multicolumn{8}{|l|}{ Parameter Settings } \\
\hline Domestic/Foreign Elasticity & 1.0 & 1.5 & 2.0 & 2.5 & 2.0 & 1.0 & 1.0 \\
\hline Foreign/Foreign Elasticity & 1.0 & 1.5 & 2.0 & 2.5 & 1.0 & 2.0 & 1.0 \\
\hline Adjustment Costs & $20 \%$ & $20 \%$ & $20 \%$ & $20 \%$ & $20 \%$ & $20 \%$ & $10 \%$ \\
\hline \multicolumn{8}{|l|}{ United States } \\
\hline Carbon Permit Price $(95 \$)$ & $\$ 87$ & $\$ 83$ & $\$ 83$ & $\$ 83$ & $\$ 81$ & $\$ 85$ & \\
\hline Carbon Emissions Change (MMTC) & -526 & -517 & -523 & -529 & -510 & -528 & -562 \\
\hline GDP, $\%$ change & $-0.4 \%$ & $-0.7 \%$ & $-0.8 \%$ & $-0.8 \%$ & $-0.7 \%$ & $-0.6 \%$ & $-0.3 \%$ \\
\hline GNP, $\%$ change & $-0.6 \%$ & $-0.8 \%$ & $-0.8 \%$ & $-0.8 \%$ & $-0.8 \%$ & $-0.7 \%$ & $-0.6 \%$ \\
\hline Change in Net Investment (Bil. 95 \$) & $-\$ 451$ & $-\$ 233$ & $-\$ 137$ & $-\$ 77$ & $-\$ 257$ & $-\$ 306$ & $-\$ 675$ \\
\hline Real Exchange Rate, $\%$ change & $10.5 \%$ & $3.3 \%$ & $1.8 \%$ & $1.1 \%$ & $1.9 \%$ & $5.7 \%$ & $13.5 \%$ \\
\hline \multicolumn{8}{|l|}{ Japan } \\
\hline Carbon Permit Price $(95 \$)$ & $\$ 112$ & $\$ 147$ & $\$ 159$ & $\$ 164$ & $\$ 146$ & $\$ 145$ & $\$ 128$ \\
\hline Carbon Emissions Change (MMTC) & -67 & -81 & -89 & -92 & -81 & -80 & -82 \\
\hline GDP, $\%$ change & $-0.6 \%$ & $-0.5 \%$ & $-0.6 \%$ & $-0.6 \%$ & $-0.5 \%$ & $-0.6 \%$ & $-0.8 \%$ \\
\hline GNP, $\%$ change & $-0.5 \%$ & $-0.6 \%$ & $-0.6 \%$ & $-0.7 \%$ & $-0.6 \%$ & $-0.6 \%$ & $-0.6 \%$ \\
\hline Change in Net Investment (Bil. $95 \$$ ) & $-\$ 55$ & $-\$ 59$ & $-\$ 67$ & $-\$ 71$ & $-\$ 100$ & $-\$ 55$ & $-\$ 26$ \\
\hline Real Exchange Rate, $\%$ change & $-5.8 \%$ & $0.7 \%$ & $1.0 \%$ & $0.9 \%$ & $0.6 \%$ & $-0.2 \%$ & $-9.9 \%$ \\
\hline \multicolumn{8}{|l|}{ Australia } \\
\hline Carbon Permit Price (95 \$) & $\$ 181$ & $\$ 182$ & $\$ 185$ & $\$ 188$ & $\$ 181$ & $\$ 184$ & $\$ 181$ \\
\hline Carbon Emissions Change (MMTC) & -48 & -49 & -50 & -50 & -49 & -49 & -48 \\
\hline GDP, $\%$ change & $-1.8 \%$ & $-2.0 \%$ & $-2.1 \%$ & $-2.1 \%$ & $-2.0 \%$ & $-2.0 \%$ & $-1.5 \%$ \\
\hline GNP, $\%$ change & $-1.6 \%$ & $-1.7 \%$ & $-1.7 \%$ & $-1.7 \%$ & $-1.7 \%$ & $-1.7 \%$ & $-1.4 \%$ \\
\hline Change in Net Investment (Bil. 95 \$) & $\$ 29$ & $\$ 37$ & $\$ 38$ & $\$ 38$ & $\$ 39$ & $\$ 37$ & $\$ 13$ \\
\hline Real Exchange Rate, $\%$ change & $2.1 \%$ & $-0.2 \%$ & $0.1 \%$ & $0.4 \%$ & $0.0 \%$ & $0.3 \%$ & $4.8 \%$ \\
\hline \multicolumn{8}{|l|}{ Other OECD } \\
\hline Carbon Permit Price $(95 \$)$ & $\$ 261$ & $\$ 248$ & $\$ 246$ & $\$ 244$ & $\$ 249$ & $\$ 246$ & $\$ 269$ \\
\hline Carbon Emissions Change (MMTC) & -461 & -419 & -412 & -409 & -419 & -417 & -484 \\
\hline GDP, $\%$ change & $-1.5 \%$ & $-1.2 \%$ & $-1.2 \%$ & $-1.2 \%$ & $-1.2 \%$ & $-1.3 \%$ & $-1.5 \%$ \\
\hline GNP, $\%$ change & $-1.3 \%$ & $-1.1 \%$ & $-1.1 \%$ & $-1.1 \%$ & $-1.1 \%$ & $-1.1 \%$ & $-1.3 \%$ \\
\hline Change in Net Investment (Bil. 95 \$) & $\$ 370$ & $\$ 220$ & $\$ 160$ & $\$ 122$ & $\$ 240$ & $\$ 274$ & $\$ 516$ \\
\hline Real Exchange Rate, $\%$ change & $-13.5 \%$ & $-2.4 \%$ & $-0.9 \%$ & $-0.3 \%$ & $-1.4 \%$ & $-4.4 \%$ & $-17.1 \%$ \\
\hline \multicolumn{8}{|l|}{ China } \\
\hline Carbon Emissions Change (MMTC) & -12 & -3 & -2 & -1 & -3 & -4 & -15 \\
\hline GDP, $\%$ change & $-0.2 \%$ & $-0.1 \%$ & $0.0 \%$ & $0.0 \%$ & $0.0 \%$ & $-0.1 \%$ & $-0.2 \%$ \\
\hline GNP, $\%$ change & $-0.1 \%$ & $0.0 \%$ & $0.0 \%$ & $0.0 \%$ & $0.1 \%$ & $0.0 \%$ & $-0.1 \%$ \\
\hline Change in Net Investment (Bil. 95 \$) & $\$ 34$ & $\$ 18$ & $\$ 12$ & $\$ 8$ & $\$ 17$ & $\$ 20$ & $\$ 59$ \\
\hline Real Exchange Rate, $\%$ change & $-4.7 \%$ & $-2.2 \%$ & $-1.5 \%$ & $-1.3 \%$ & $-1.9 \%$ & $-2.4 \%$ & $-6.5 \%$ \\
\hline \multicolumn{8}{|l|}{ LDCs } \\
\hline Carbon Emissions Change (MMTC) & 79 & 38 & 38 & 39 & 38 & 41 & 96 \\
\hline GDP, $\%$ change & $0.4 \%$ & $0.0 \%$ & $0.0 \%$ & $0.0 \%$ & $0.0 \%$ & $0.1 \%$ & $0.6 \%$ \\
\hline GNP, $\%$ change & $0.7 \%$ & $0.1 \%$ & $0.1 \%$ & $0.1 \%$ & $0.1 \%$ & $0.2 \%$ & $0.9 \%$ \\
\hline Change in Net Investment (Bil. $95 \$$ ) & $\$ 144$ & $\$ 56$ & $\$ 38$ & $\$ 29$ & $\$ 110$ & $\$ 89$ & $\$ 171$ \\
\hline
\end{tabular}



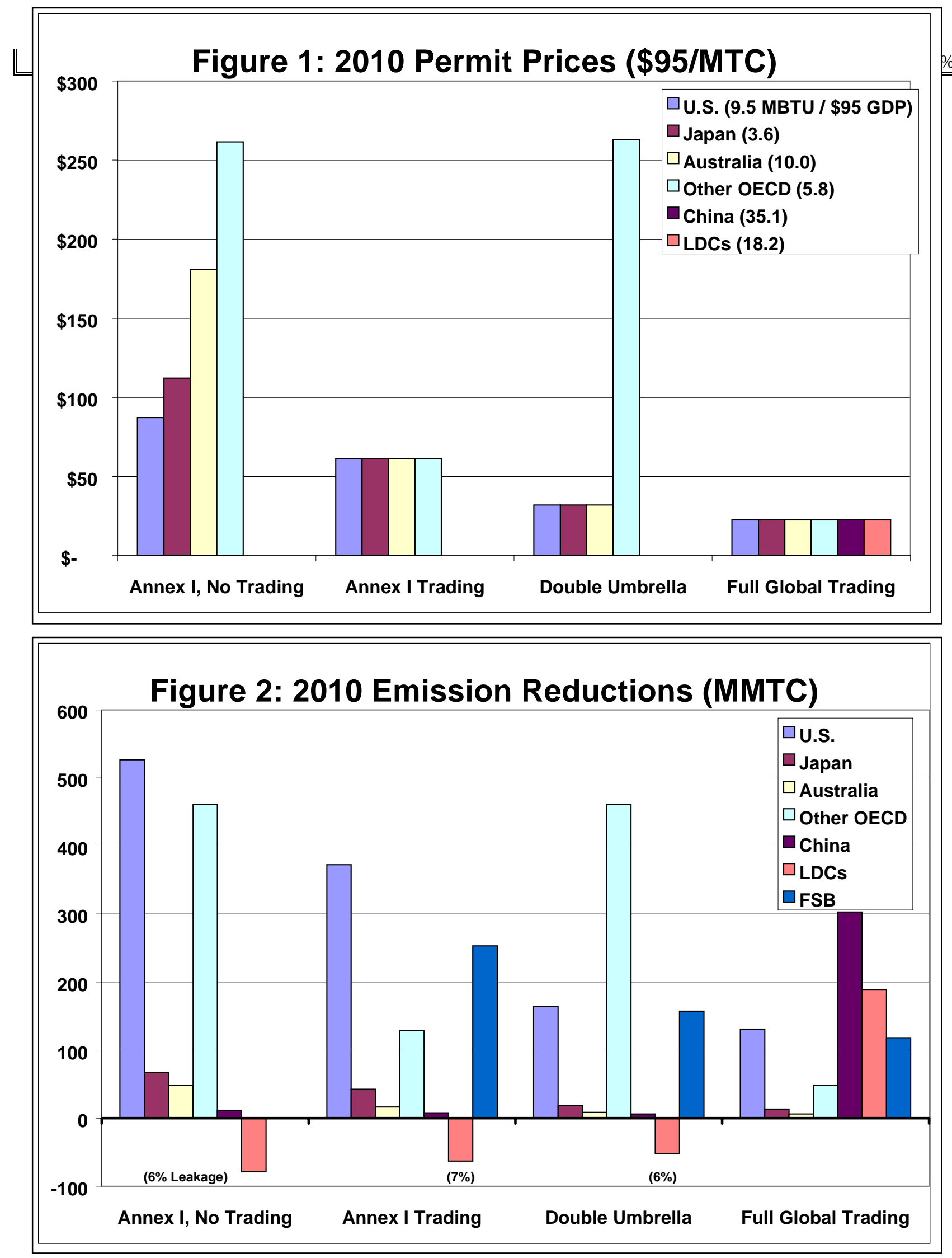

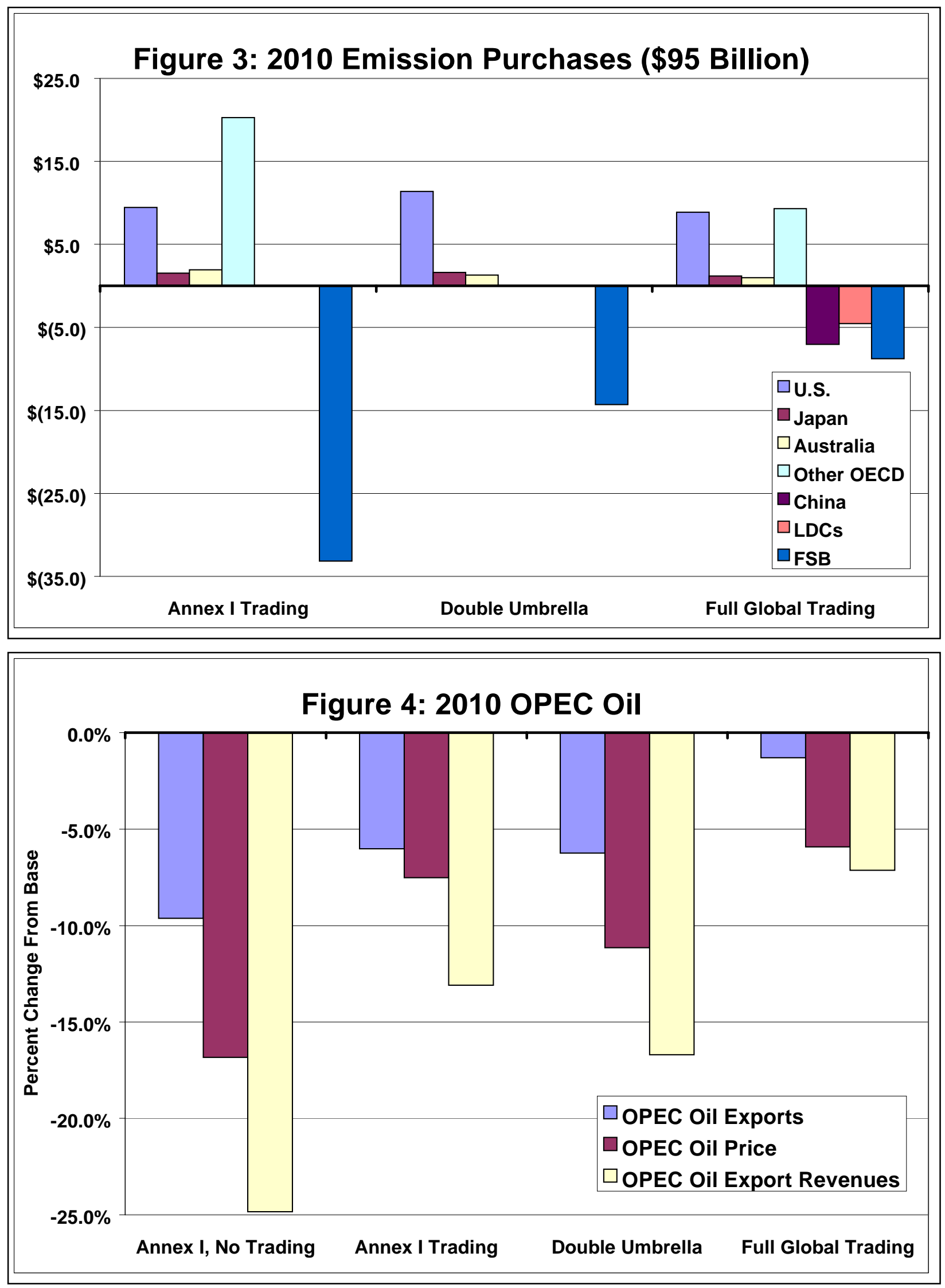

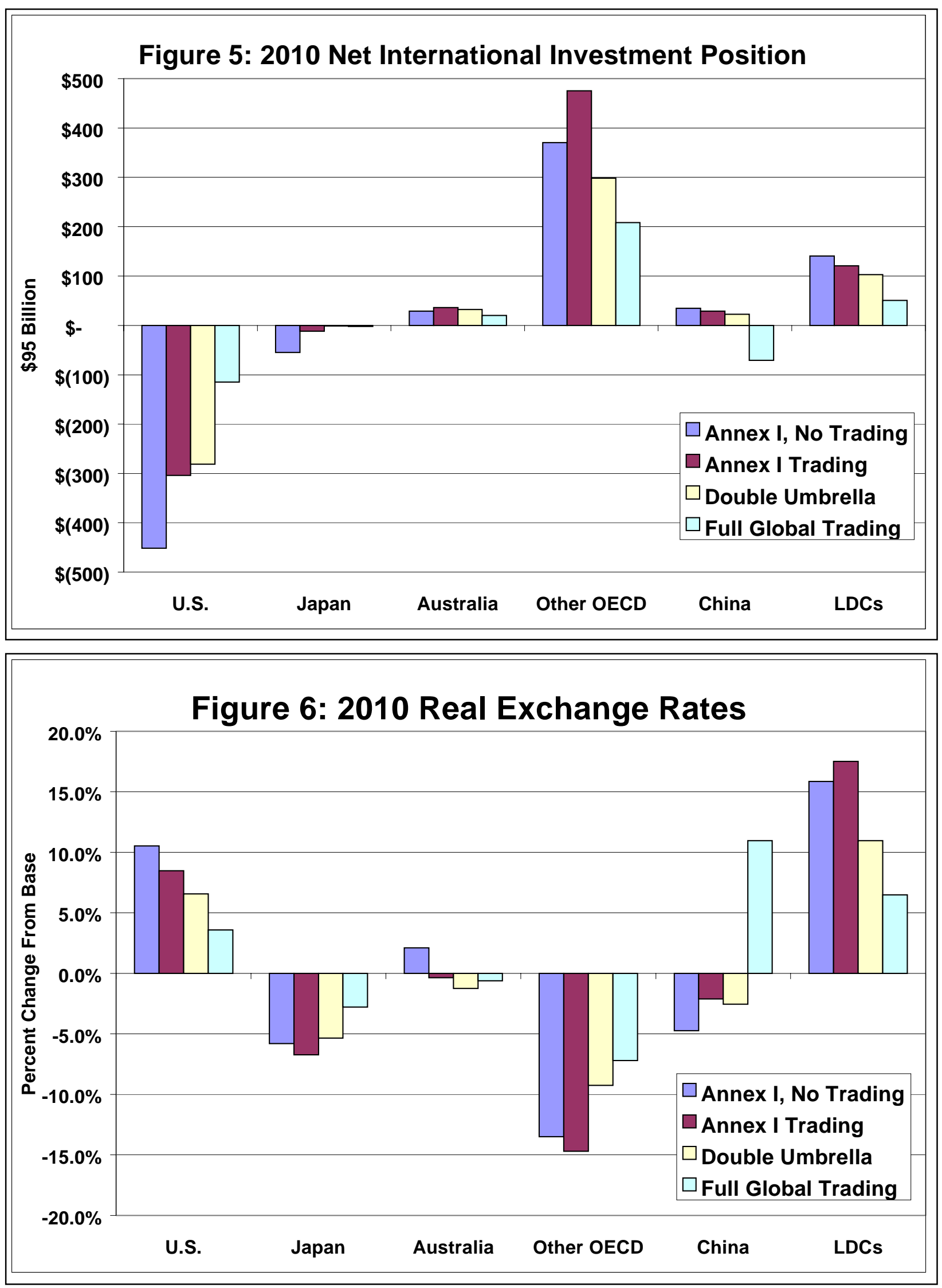

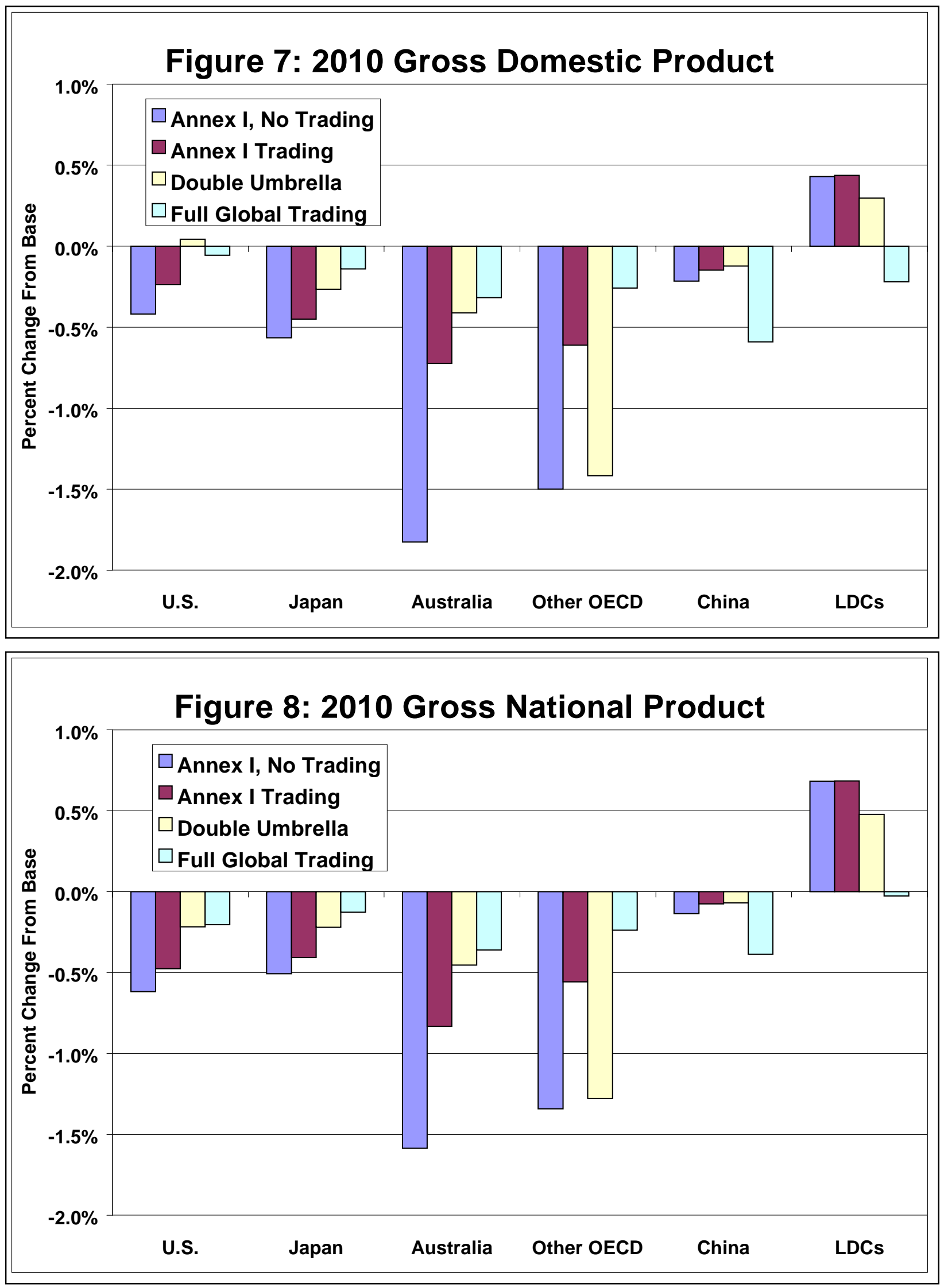
Figure 9: 2010 Exports

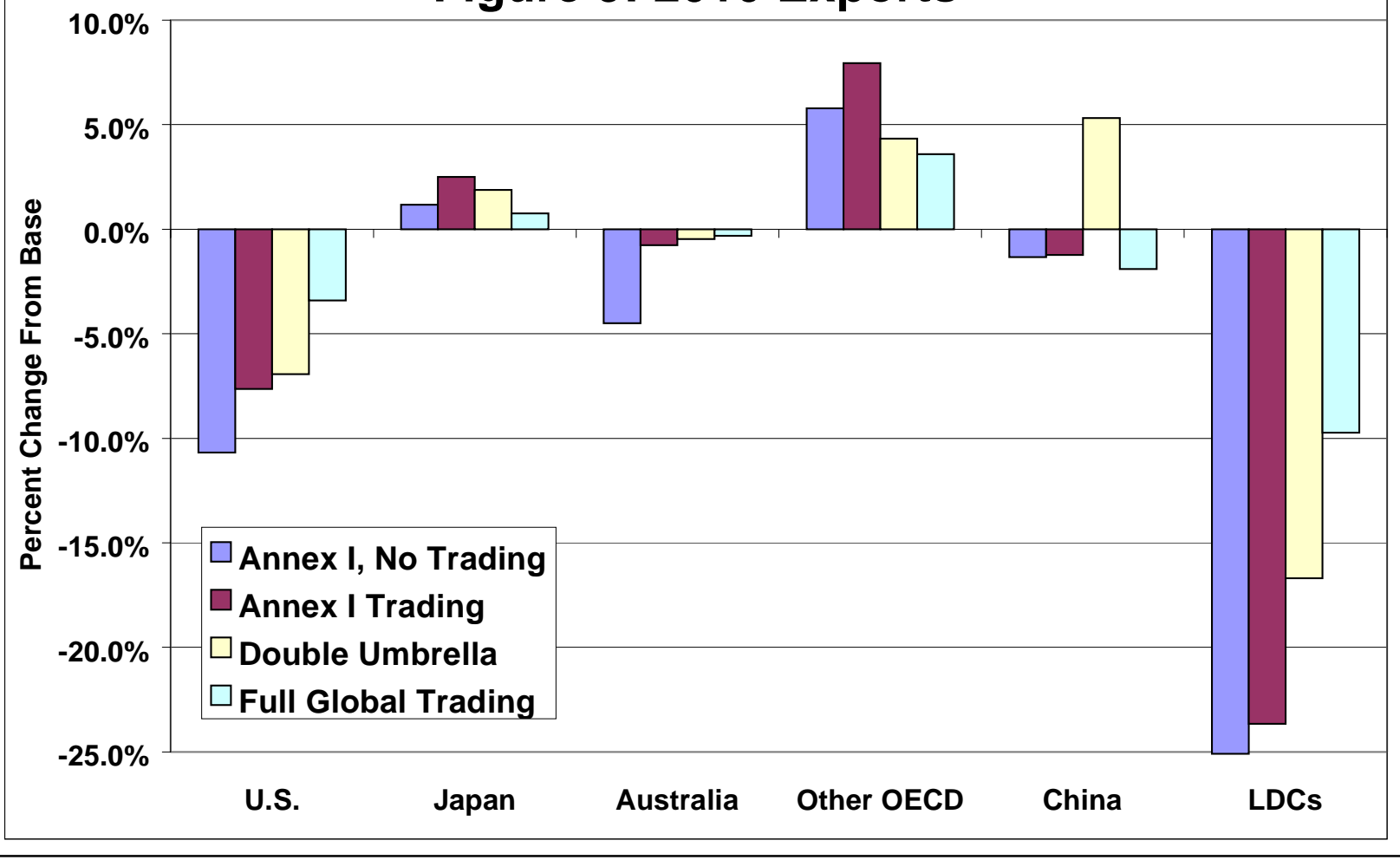

Figure 10: 2010 Permit Prices (\$95/MTC)

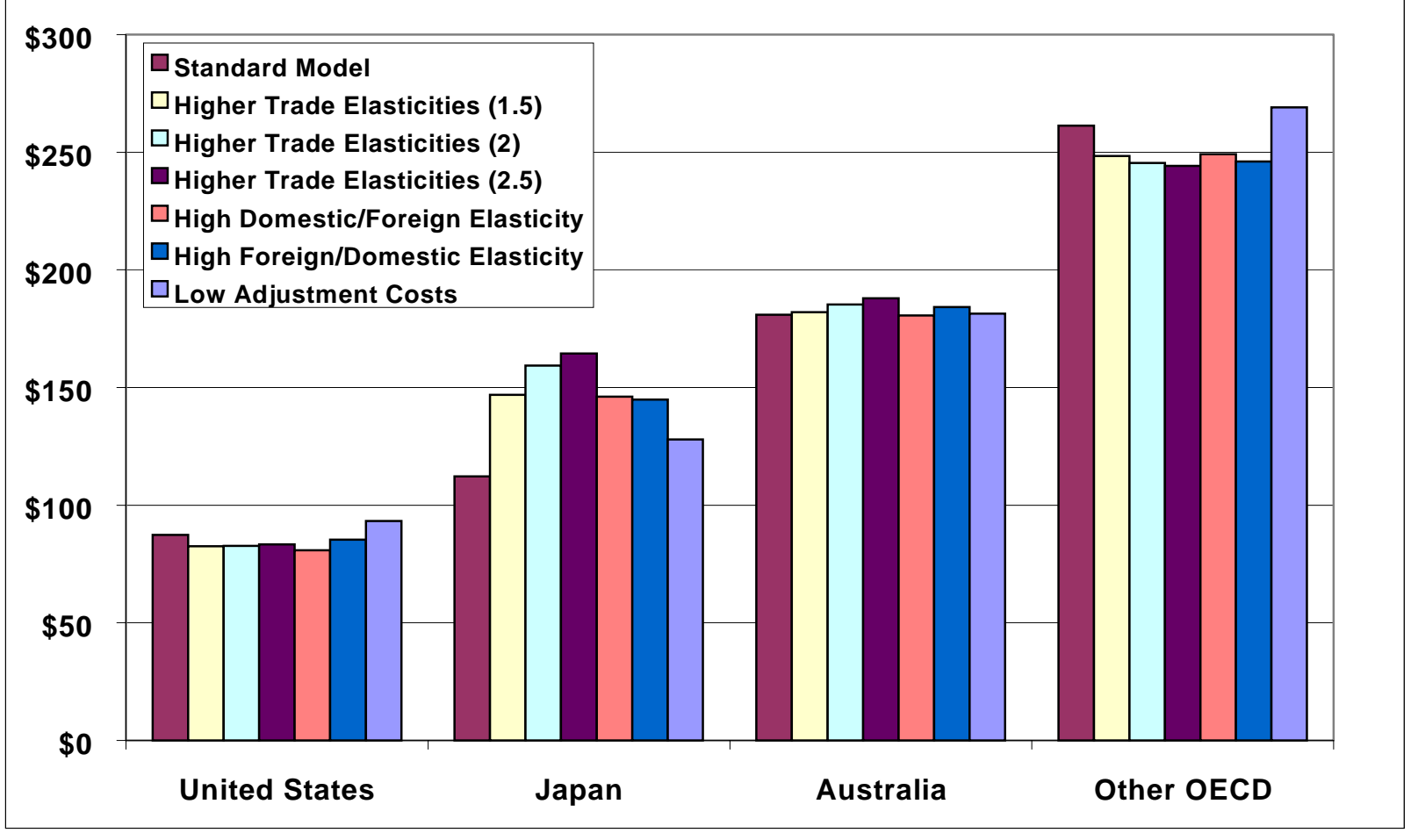



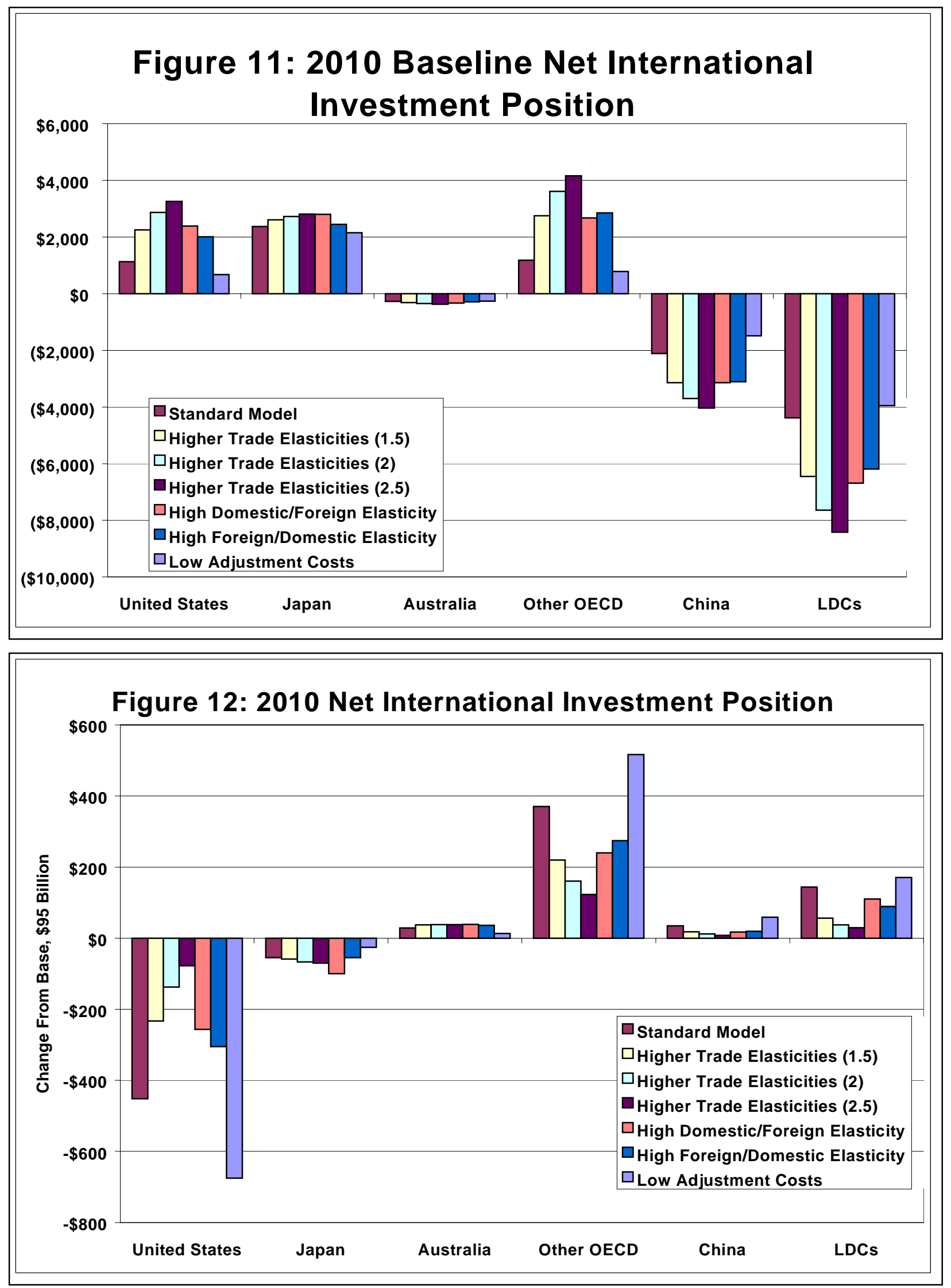

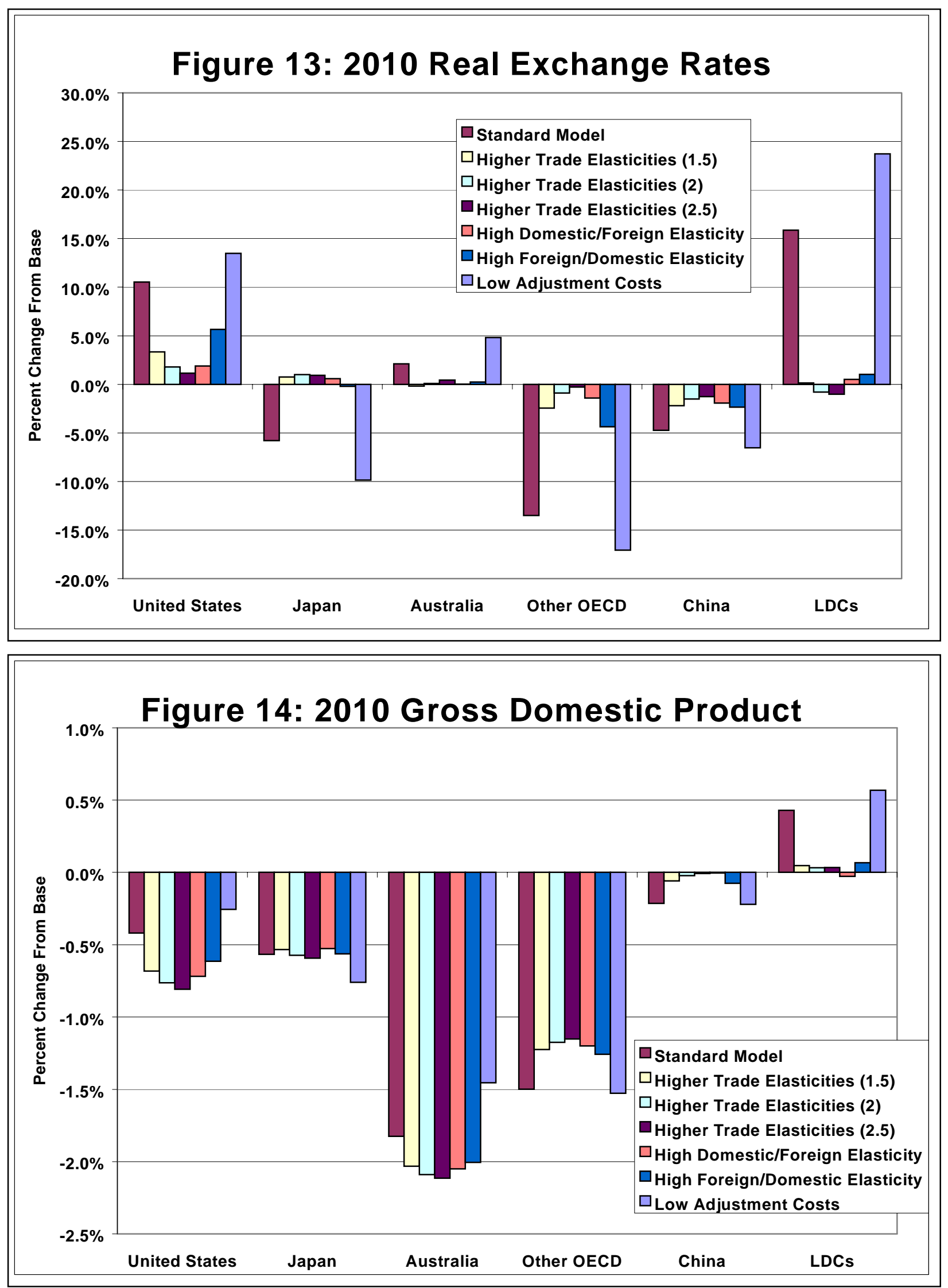

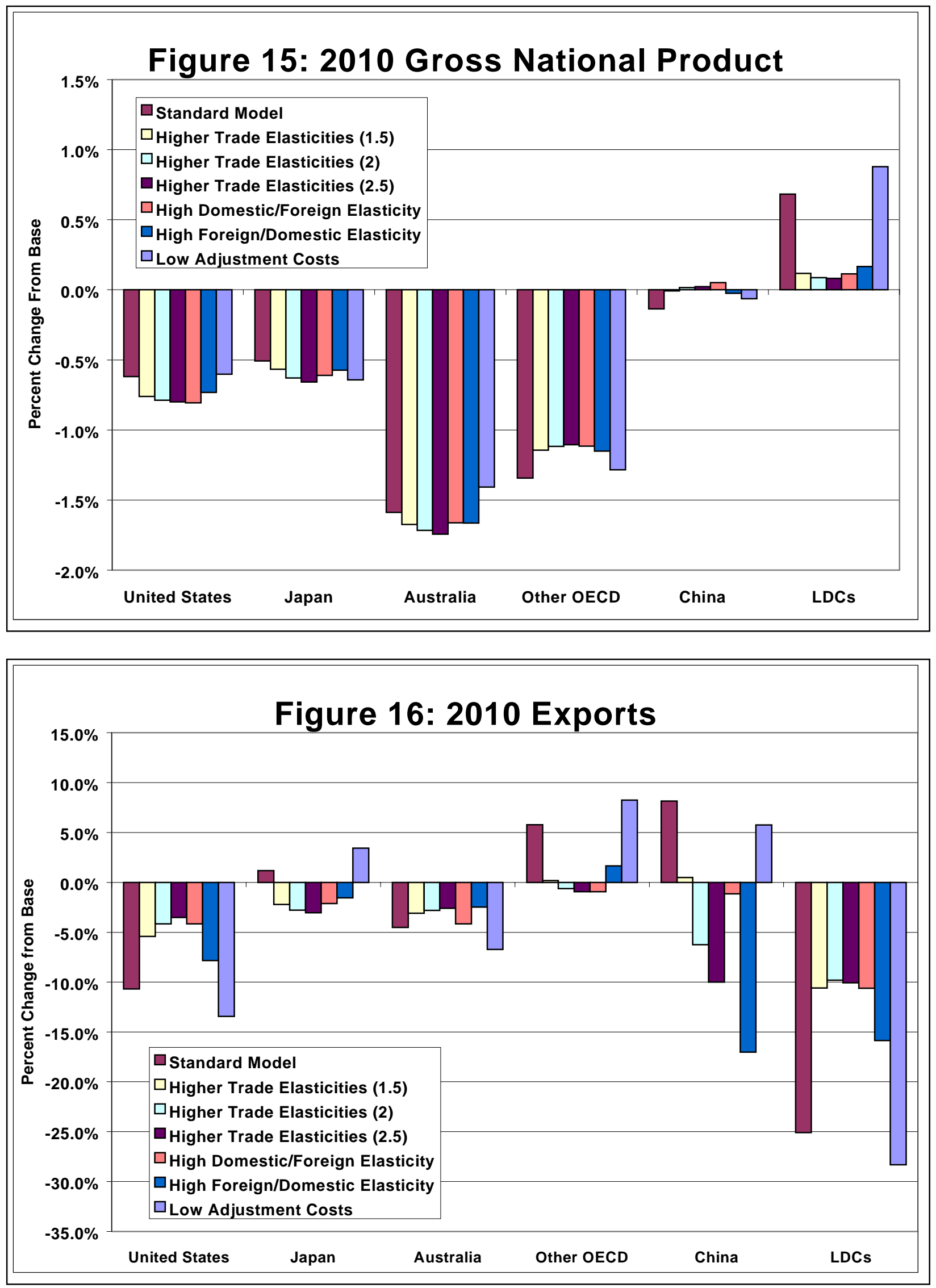